\title{
Computational Biotransformation Profile of Emerging Phenolic Pollutants by Cytochromes P450: Phenol Coupling Mechanism
}

Guo, Fangjie; Chai, Lihong; Zhang, Shubin; Yu, Haiying; Liu, Weiping; Kepp, Kasper Planeta; Ji, Li

Published in:

Environmental Science and Technology

Link to article, DOI:

10.1021/acs.est.9b06897

Publication date:

2020

Document Version

Peer reviewed version

Link back to DTU Orbit

Citation (APA):

Guo, F., Chai, L., Zhang, S., Yu, H., Liu, W., Kepp, K. P., \& Ji, L. (2020). Computational Biotransformation Profile of Emerging Phenolic Pollutants by Cytochromes P450: Phenol Coupling Mechanism. Environmental Science and Technology, 54(5), 2902-2912. https://doi.org/10.1021/acs.est.9b06897

\section{General rights}

Copyright and moral rights for the publications made accessible in the public portal are retained by the authors and/or other copyright owners and it is a condition of accessing publications that users recognise and abide by the legal requirements associated with these rights.

- Users may download and print one copy of any publication from the public portal for the purpose of private study or research.

- You may not further distribute the material or use it for any profit-making activity or commercial gain

- You may freely distribute the URL identifying the publication in the public portal 

Pollutants by Cytochromes P450: Phenol Coupling Mechanism

Fangjie Guo, Lihong Chai, Shubin Zhang, Haiying Yu, Weiping Liu, Kasper P. Kepp, and Li Ji

Environ. Sci. Technol., Just Accepted Manuscript • DOI: 10.1021/acs.est.9b06897 • Publication Date (Web): 22 Jan 2020

Downloaded from pubs.acs.org on January 28, 2020

\section{Just Accepted}

"Just Accepted" manuscripts have been peer-reviewed and accepted for publication. They are posted online prior to technical editing, formatting for publication and author proofing. The American Chemical Society provides "Just Accepted" as a service to the research community to expedite the dissemination of scientific material as soon as possible after acceptance. "Just Accepted" manuscripts appear in full in PDF format accompanied by an HTML abstract. "Just Accepted" manuscripts have been fully peer reviewed, but should not be considered the official version of record. They are citable by the Digital Object Identifier (DOI®). "Just Accepted" is an optional service offered to authors. Therefore, the "Just Accepted" Web site may not include all articles that will be published in the journal. After a manuscript is technically edited and formatted, it will be removed from the "Just Accepted" Web site and published as an ASAP article. Note that technical editing may introduce minor changes to the manuscript text and/or graphics which could affect content, and all legal disclaimers and ethical guidelines that apply to the journal pertain. ACS cannot be held responsible for errors or consequences arising from the use of information contained in these "Just Accepted" manuscripts. 


\section{Computational Biotransformation Profile of}

2 Emerging Phenolic Pollutants by Cytochromes P450:

5 Fangjie Guo, ${ }^{1+}$ Lihong Chai, ${ }^{1+}$ Shubin Zhang, ${ }^{2,3}$ Haiying Yu, ${ }^{4}$ Weiping Liu, ${ }^{1}$ Kasper P. Kepp, ${ }^{5}$ and $\mathrm{Li} \mathrm{Ji}^{*, 1,3}$

$7{ }^{1}$ College of Environmental and Resource Sciences, Zhejiang University, Yuhangtang Road 866, Hangzhou 310058, China

$9{ }^{2}$ CAS Key Laboratory of Tropical Forest Ecology, Xishuangbanna Tropical Botanical Garden, Chinese Academy of Sciences, Mengla, Yunnan 666303, China

$11{ }^{3}$ Graduate School of Agriculture, Kyoto University, Kitashirakawa Oiwake-cho, Sakyo-ku, Kyoto 606-8502, Japan

$13{ }^{4}$ College of Geography and Environmental Sciences, Zhejiang Normal University, Yingbin Avenue 688, Jinhua 321004, P.R. China

$15{ }^{5}$ DTU Chemistry, Technical University of Denmark, Building 206, Kgs. Lyngby, DK-2800, 16 Denmark 


\section{Abstract}

18 Phenols are ubiquitous environmental pollutants, whose biotransformation involving phenol

19 coupling catalyzed by cytochromes P450, may produce more lipophilic and toxic metabolites.

20 DFT computations were performed to explore the debated phenol coupling mechanisms, taking

21 triclosan as a model substrate. We find that a diradical pathway facilitated by Compound I and

22 protonated Compound II of P450 is favored vs. alternative radical-addition or electron-transfer

23 mechanisms. The identified diradical coupling resembles a "two-state reactivity" from

24 Compound I characterized by significantly high rebound barriers of the phenoxy radicals, which

25 can be formulated into three equations for calculating the ratio [coupling]/[hydroxylation]. A

26 higher rebound barrier than H-abstraction for triclosan in the high-spin state can facilitate the

27 phenoxy radical dissociation and thus to enable phenol coupling, while H-abstraction/radical-

28 rebound causing phenol hydroxylation via minor rebound barriers mostly occur in the low-spin

29 state. Therefore, oxidation of triclosan by $\mathrm{P} 450$ fits the first equation with a ratio

30 [coupling]/[hydroxylation] of 1:4, consistent with experimental data indicating different extents

31 of triclosan coupling (6-40\%). The high rebound barrier of phenoxy radicals, as a key for the

32 mechanistic identification of phenol coupling vs. hydroxylation, originates from their weak

33 electron donor ability due to spin aromatic delocalization. We envision that the revealed

34 mechanism can be extended to the cross-coupling reactions between different phenolic pollutants, 35 and the coupling reactions of several other aromatic pollutants, to infer unknown metabolites. 


\section{Introduction}

41 Oxidative phenol couplings catalyzed by cytochromes P450 (P450) occur widely during

42 natural product biosynthesis, e.g. phenol couplings are necessary for alkaloid and antibiotic

43 biosynthesis in plants. ${ }^{1-4}$ In the meantime, phenolic xenobiotics distribute ubiquitously in the 44 environment, ${ }^{5-9}$ such as a significant proportion of pharmaceuticals and personal care products

45 (PPCPs) contain phenolic moieties, and many emerging pollutants with phenolic residues can be

46 formed readily via aromatic hydroxylation, which may undergo P450 biotransformation via

47 phenol coupling to produce more lipophilic metabolites with higher toxicity; for example, more

48 estrogenic products have been detected within and among triclosan and several other phenolic

49 pollutants such as bisphenol A (BPA) in both in vitro and in vivo assays. ${ }^{10}$ A full understanding

50 of these metabolic mechanisms is necessary for accurately estimating the occurrence and

51 possibility of specific phenol coupling reactions, which can then provide the putative metabolites

52 for exploring the potential toxicological effects of phenolic pollutants with susceptibility to

53 metabolism in organisms.

$54 \quad$ The concept of phenol coupling as a diradical mechanism was proposed as far back as 1957

55 for alkaloid salutaridine biosynthesis by C-C coupling of $R$-reticuline. ${ }^{11}$ With the advancement of

56 P450 chemistry, its active species was recognized as the remarkable iron(IV)-oxo heme cation

57 radical cofactor known as compound I (Cpd I) (Scheme 1, top). ${ }^{12,13}$ The diradical mechanism,

58 shown in Scheme 1(i), has been thought to involve the initial abstraction of a phenolic $\mathrm{H}$-atom

59 by Cpd I to create a phenoxy radical and the protonated iron-hydroxo species Cpd II.

60 Subsequently, this phenoxy radical rotates or another phenolic substrate approaches in

61 juxtaposition to the iron of protonated Cpd II, leading to abstraction of another phenolic 
62 hydrogen atom and formation of a second phenoxy radical, followed by inter- or intramolecular

63 phenol couplings within a catalytic cycle of the P450 enzyme. ${ }^{1,14,15}$

64 Scheme 1. Structure of Compound I of P450 and Alternative Mechanisms for Phenol-Coupling

65 Catalyzed by $\mathrm{P} 450$
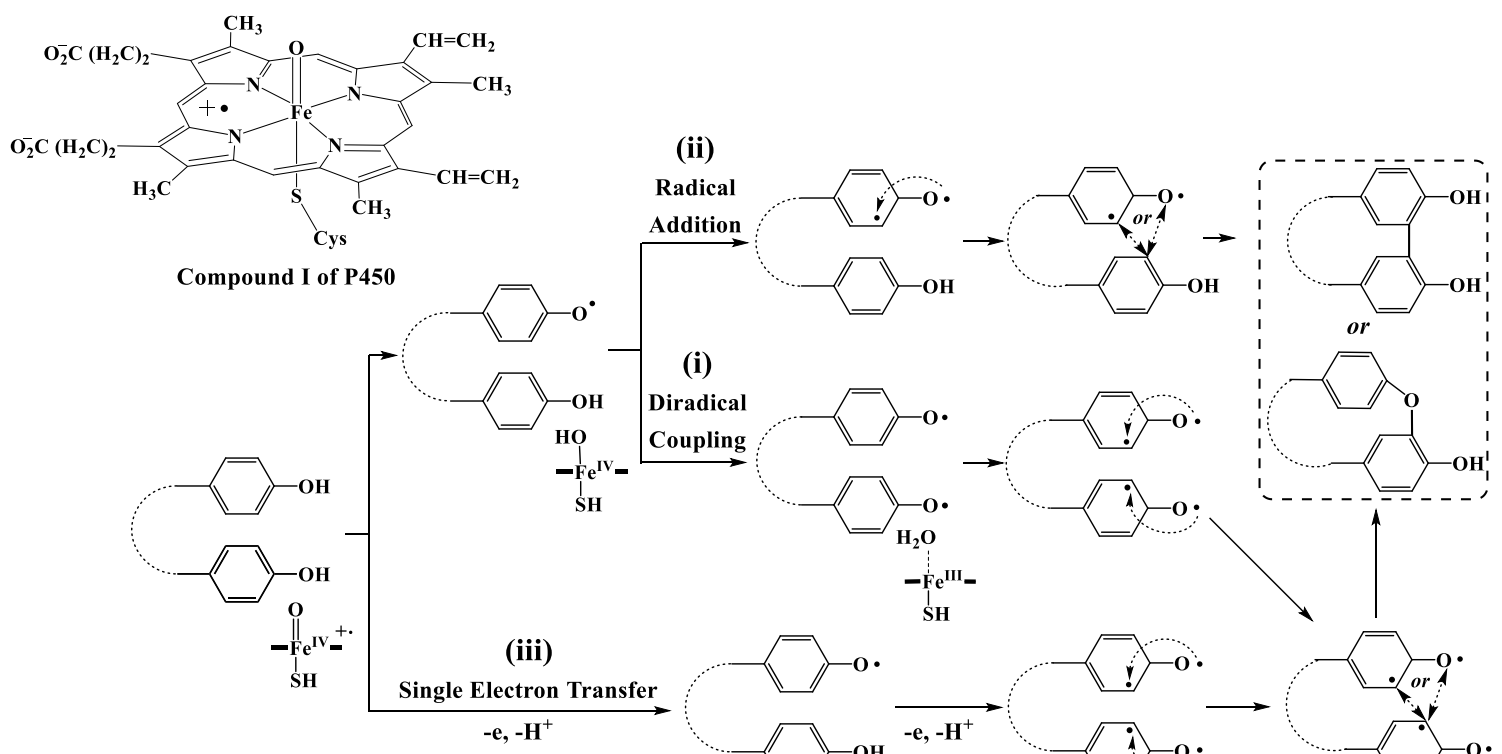

(i)
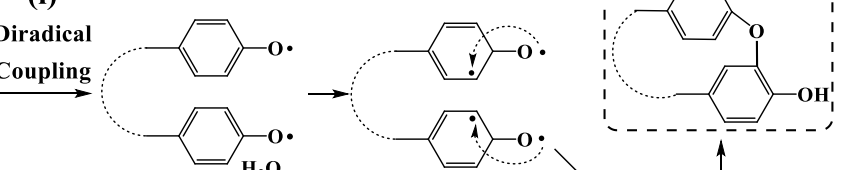

$|*| \quad \cdots \cdot$ represents spin delocalization

Another possible coupling pathway is radical addition to the $\pi$-ring, as shown in Scheme

1(ii). ${ }^{1}$ If the diradical or radical addition enables oxidative phenol coupling, the phenoxy radical needs long lifetime. Several studies indicate that the radicals formed in P450-catalyzed oxidative

70 reactions are relatively short-lived and restricted in their motions, in favor of $\mathrm{H}-$

71 abstraction/phenoxy-radical rebound leading to aromatic hydroxylation as supported by the

72 tendency of H-abstraction from phenols. ${ }^{16-19}$ Therefore, the major bottleneck to explain the

73 traditionally proposed radical mechanism especially the diradical mechanism is that why

74 normally short-lived radicals herein have enough long lifetime to enable phenoxy radical

75 coupling. In addition, oxidative coupling of phenolic compounds through consecutive electron-

76 transfer (ET) steps is considered the most typical peroxidation reaction catalyzed by peroxidases 
77 such as horseradish peroxidase (HRP). ${ }^{20-23}$ Since both HRP and P450 are heme enzymes, the 78 possibility that $\mathrm{P} 450$ performs oxidative coupling reactions of phenols is of substantial interest,

79 as shown in Scheme 1(iii). ${ }^{1}$ We expect that HRP with its computed larger electron affinity of 80 Cpd I (6.41 eV) may more readily participate in ET reactions than P450 $(3.06 \mathrm{eV}) .{ }^{24}$ Therefore, 81 the mechanism of phenol coupling poses a fascinating dilemma.

82 Computational analysis can reveal the electronic structure properties determining 83 transformation mechanisms of environmental pollutants, ${ }^{25-30}$ which has been performed on P450

84 oxygenation reactions leading to the concept of two-state reactivity (TSR) of Cpd I to resolve the 85 "rebound controversy" of alkane hydroxylation, ${ }^{31-36}$ as well as other mechanistic controversies in 86 alkene epoxidation, ${ }^{37}$ nitrosamine denitrosation, ${ }^{38}$ alkane desaturation ${ }^{39}$ and so on. According to

87 TSR, the alkyl radicals and iron-hydroxy species are produced by Cpd I through H-abstraction 88 on two closely-lying spin surfaces involving a high-spin (HS, quartet) and low-spin (LS, doublet)

89 states, which then react differently; in the LS state, the alkyl radicals rebound onto the iron90 hydroxy intermediate to generate the alcohol complex with no product rearrangement since the 91 rebound is essentially barrierless, thus the radical lifetime is negligible whereas in the HS state

92 the barrier for rebound is small but significant (1-5 kcal $/ \mathrm{mol})$; accordingly, the radical lifetime is 93 relatively long such that the radical rebound after rearrangement can compete with direct 94 rebound..$^{31,32,34,40,41}$ Since the initial H-abstraction is rate-determining in both spin states, the 95 existence of other competitive pathways for alkyl radicals was considered unlikely, although the 96 dissociation of radicals from the P450 active site requires very little energy. ${ }^{41}$ However, the 97 radical dissociation pathway has proven prominent in the area of synthetic iron-oxo 98 complexes. ${ }^{35,42-45}$ Although phenol coupling by P450 should inherently relate to the non-rebound 
99 mechanism, this mechanism, to our knowledge, remains unexplored in the context of P450 100 reactivity.

101 We have recently shown that P450-catalyzed aromatic hydroxylation of bisphenols and 102 alkylphenols proceeds via H-abstraction/phenoxy-radical rebound on the LS surface, due to the 103 fact that the phenoxy radical rebound onto the aromatic ring in the HS state has higher barriers 104 than the initial H-abstraction barrier. ${ }^{46}$ Studies of CYP2D6 indicate that dopamine synthesis is 105 facilitated by $\mathrm{H}$-abstraction/phenoxy-radical rebound, with a very high barrier (19 kcal/mol) for 106 the phenoxy radical rebound onto the aromatic ring. ${ }^{47}$ However, we hypothesize that these 107 radical-rebound steps can be less favorable than other non-rebound reactions such as phenoxy 108 radical dissociation, which will provide a pathway to generate phenol coupling products. It is 109 unclear whether high rebound barriers of phenoxy radicals are common to P450-catalyzed 110 phenol oxidations and whether this makes phenoxy radical dissociation and phenol coupling 111 products possible. This would greatly affect the mechanistic relationship between phenol 112 coupling and hydroxylation and thus deserves to be addressed in mechanistic detail.

113 In order to elucidate the complete scenario of P450-dependent phenol coupling, we 114 performed density functional theory (DFT) in investigating the phenol coupling reactions. 115 Triclosan, one commonly used antibacterial ingredient and one of the widely concerned PPCP 116 pollutants, was selected to get the complete mechanistic picture of phenol coupling, with 117 available experimental data to confirm the derived mechanisms. ${ }^{10}$ As will be shown, this work 118 provides the fundamental insight into how do the phenol coupling reactions catalyzed by P450 119 proceed based on the high rebound barrier of phenoxy radical within the framework of "two-state 120 reactivity", and such coupling mechanism can be mapped to the coupling reactions of several 121 other aromatic pollutants. 


\section{Computational Methodology}

\section{Enzymatic Reactions}

124 Level of Theory. As in previous studies, ${ }^{39,48,49}$ the six-coordinate tri-radicaloid ferryl 125 complex $\mathrm{Fe}^{4+} \mathrm{O}^{2-}\left(\mathrm{C}_{20} \mathrm{~N}_{4} \mathrm{H}_{12}\right)^{-1}(\mathrm{SH})^{-1}$ was used to model the enzymatic active site of Cpd I of P450.

126 The geometries were optimized with unrestricted DFT using the B3LYP hybrid density 127 functional $1^{50,51}$ with the LANL2DZ basis set $^{52}$ for iron and 6-31G** for other atoms (denoted 128 BSI). B3LYP was used since it can reproduce the measured kinetic isotope effects ${ }^{53}$ and electron 129 paramagnetic resonance parameters for penta-coordinated heme, ${ }^{54}$ generates geometries 130 consistent with crystal structures, ${ }^{55}$ and shows qualitatively accurate relative energies vs. 131 benchmark CASSCF calculations. ${ }^{56}$ The basis-set superposition error (BSSE) was shown to be 132 very small for reactant complexes in P450-catalyzed reactions by DFT-B3LYP method, ${ }^{31}$ so this 133 work did not consider the minor contributions of BSSE to the energies. The vibrational 134 frequencies were calculated to confirm the nature of all ground states (no imaginary frequencies) 135 and transition states (one imaginary frequency), while the intrinsic reaction coordinate (IRC) 136 approach was used to verify the connection from transition state to its reactant and product. The 137 computed vibrational frequencies were used further for quantifying the zero-point energy 138 correction $(\mathrm{ZPE})$ as well as the thermal contributions to the Gibbs free energy at $\mathrm{T}=298.15 \mathrm{~K}$ 139 and $1 \mathrm{~atm}$ pressure.

140 For better estimating Gibbs free energies, single-point calculations were done using the 141 LANL2DZ basis set for iron and the $6-31+\mathrm{G}^{* *}$ basis set augmented with diffuse basis functions 142 for all other atoms (denoted BSII), employing the polarizable continuum solvation model $143(\mathrm{PCM})^{63}$ using chlorobenzene $(\varepsilon=5.7)$ to include solvation free energies. Chlorobenzene was 144 used because it can provide a good estimate of the polarization caused by the dipoles of the 
145 protein pocket near the axial cysteine. ${ }^{64}$ Dispersion interactions could be important in the close 146 interaction of the strained phenol rings and were thus considered by single-point calculations 147 with the B3LYP-D3/BSI level since B3LYP itself does not include dispersion. ${ }^{66}$ The relative 148 Gibbs free energies of the P450 oxidation reactions shown below were estimated by combining 149 PCM solvation (chlorobenzene) single-point energies at B3LYP/BSII level and dispersion 150 corrections, as well as thermochemical contributions to free energy from optimizations at the BSI 151 level, unless pointed out specifically.

152 Variation of DFT Functional and Basis Set. In order to further access the sensitivity of 153 the reaction mechanism toward the choice of density functional, we performed single-point 154 calculations with other hybrid, local, and non-hybrid functionals, i.e. TPSSh, ${ }^{57,58}$ B3PW91, ${ }^{51,59}$ 155 BLYP, ${ }^{50,60}$ MPW1PW91 ${ }^{61}$ and M06L ${ }^{62}$ om the B3LYP/BSI optimized geometries. Whereas 156 absolute barriers and intermediate energies changed to some extent, we found that the relative 157 pathway energies, and thus the reaction preferences and overall qualitative picture were similar 158 with all the functionals (Table S10), and the main findings on the relative preference of the 159 pathways are thus insensitive to method choice.

160 To access whether the effect of diffuse basis functions on geometry optimizations influence 161 the mechanism, we reoptimized the inner-sphere oxidation pathway of triclosan in the HS state at 162 the B3LYP/BSII level followed by analytical frequency calculations. The results provide the 163 same mechanistic picture with only minor geometric differences from those done with BSI 164 (Figure S1). We also tested the basis set effect of the single-point calculations on the H165 abstraction from the phenolic group, O-addition onto the aromatic ring of triclosan, and phenoxy 166 radical rebound steps, using the SDD basis set on iron coupled to the $6-311++\mathrm{G}^{* *}$ basis set for 
167 other atoms; the result gives just few energetic discrepancies compared to the results got from 168 the BSII level (Table S12).

169 Variation of Solution and Solvation Model. To evaluate the sensitivity of our results to 170 the solution choice, we calculated PCM energies in cyclohexane $(\varepsilon=2.0), 1$-bromopropane $(\varepsilon=$ 171 8.0), ethanol $(\varepsilon=24.9)$, and acetonitrile $(\varepsilon=35.7)$, resulting in the same qualitative picture 172 except for a minor energy difference (Tables S13). We further tested the bulk polarity effect 173 using the SMD solvation model ${ }^{65}$ in chlorobenzene, the results of which shows that the SMD 174 solvation model has very similar solvation effect to that of the PCM solvation model, analyzed 175 from the detailed comparison at both the quantitative and qualitative levels (details see Section II 176 in the Supporting Information, SI).

177 Protein Environment Effect. The quantum chemical cluster (QCC) ${ }^{67}$ and quantum 178 mechanics/molecular mechanics $(\mathrm{QM} / \mathrm{MM})^{68}$ are two recognized methods in investigating the 179 protein effects of known structure on the catalytic mechanism in enzymatic reactions. However, 180 until now there is no any study reporting the specific P450 isoforms responsible for the 181 intermolecular coupling of phenolic pollutants including triclosan, while human CYP1A2 was 182 shown to have the highest activity in metabolizing triclosan via hydroxylation into 2,4183 dichlorophenol, 4-chlorocatechol and 5'-hydroxytriclosan. ${ }^{69}$ As mechanism revealed from the 184 small Cpd I model, H-abstraction and high-barrier phenoxy radical rebound are two 185 preconditions for the phenoxy radical dissociation and subsequent phenol coupling. Therefore, 186 the QCC approach was carried out to check the reaction mechanism of $\mathrm{H}$-abstraction and 187 phenoxy radical rebound of triclosan, which treated the active site of CYP1A2 (PDB code: 2HI4) 188 with important surrounding amino acids quantum mechanically (details see Section III in the SI). 189 The QCC approach shows that the cluster model is mechanistically consistent with the Cpd I 
190 model (H-abstraction is much more favorable than O-addition, followed by phenoxy radical

191 rebound with very high rebound barrier), namely, the geometric constraints near the active site of

192 CYP1A2 do not restrict the preferred pathways obtained from the small model.

\section{Non-Enzymatic Reactions}

Radical Addition and Diradical Coupling Reactions. All geometries of various reactions

195 were optimized at the B3LYP/BSI level in both the polar (water solution, $\varepsilon=78.4$ ) and non-polar 196 (chlorobenzene solution, $\varepsilon=5.7$ ) environments with PCM. Single-point energies were computed

197 with PCM for both water and chlorobenzene with D3 dispersion corrections at the B3LYP/6$198311++\mathrm{G}^{* *}$ level. The reported reaction free energies for reactions were described by 199 B3LYP/BSIII single-point energies with solution and D3 dispersion corrections, as well as free 200 energy corrections from B3LYP/BSI geometry optimizations.

201 Molecular Property Computations. Ionization potentials (IPs), electron affinities (EAs) 202 and bond dissociation energies (BDEs) were obtained from the molecules optimized at the 203 B3LYP/BSI level in the gas phase, using single-point calculations at the B3LYP/BSIII level with 204 free energy corrections for IPs and EAs, and enthalpy corrections for the BDEs.

205 All computations of this work were performed using the Gaussian 09 D.01 program. $^{70}$

\section{Results and Discussion}

\section{Outer-Sphere Oxidation Mechanism}

208 We firstly focused on the mechanism of outer-sphere ET from the electron-rich phenolic 209 group of triclosan to Cpd I of P450 producing the phenolic radical-cation and Cpd II, according 210 to eq. (1): 


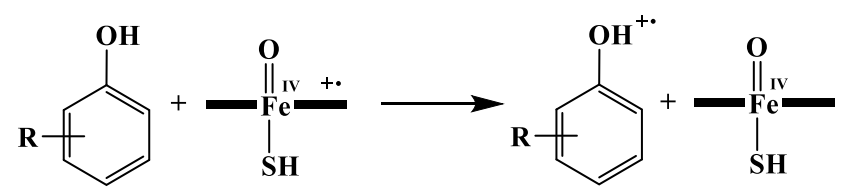

212 The free energy barriers of the outer-sphere ET $\left(\Delta G_{\mathrm{ET}}^{\neq}\right)$can be appropriately estimated from the

213 Marcus theory ${ }^{71-73}$. The Marcus theory relies on the transition-state formalism defining $\Delta \mathrm{G}^{\neq}$ET $_{\text {in }}$

214 terms of two thermodynamic parameters, the free energy of reaction $\left(\Delta \mathrm{G}_{\mathrm{ET}}\right)$ and the

215 reorganization energy $(\lambda)$, as shown in eq. 2 :

$$
\Delta \mathrm{G}_{\mathrm{ET}}^{\neq}=\frac{\lambda}{4}\left(1+\frac{\Delta \mathrm{G}_{\mathrm{ET}}}{\lambda}\right)^{2}
$$

216 The parameter $\lambda$ consists of two parts, the solvent reorganization energy $\lambda_{0}$ and the inner

217 reorganization energy $\lambda_{\mathrm{i}}$, i.e. $\lambda=\lambda_{\mathrm{i}}+\lambda_{0}$ (the details are shown in Section IV in the SI).

218 Accordingly, Table 1 shows the obtained reorganization energies, reaction energies and

219 activation barriers for the ET reaction between triclosan and Cpd I of P450.

220 Table 1. The computed reorganization energies, free energies and activation barriers for the 221 electron transfer from triclosan to Cpd I of P450 in both the HS and LS states

\begin{tabular}{ccccc}
\hline & $\begin{array}{c}\boldsymbol{\lambda}_{\mathbf{i}} \\
(\mathrm{kcal} / \mathrm{mol})\end{array}$ & $\begin{array}{c}\boldsymbol{\lambda}_{\mathbf{0}} \\
(\mathrm{kcal} / \mathrm{mol})\end{array}$ & $\begin{array}{c}\Delta \mathbf{G}_{\mathbf{E T}}^{\neq} \\
(\mathrm{kcal} / \mathrm{mol})\end{array}$ & $\begin{array}{c}\Delta \mathbf{G}_{\mathbf{E T}} \\
(\mathrm{kcal} / \mathrm{mol})\end{array}$ \\
\hline $\mathbf{H S}$ & 9.7 & 7.8 & 54.4 & 44.1 \\
$\mathbf{L S}$ & 9.9 & 12.3 & 49.1 & 43.8 \\
\hline
\end{tabular}

223 The obtained $\Delta G_{\mathrm{ET}}^{\neq}$is $54.4 / 49.1 \mathrm{kcal} / \mathrm{mol}$ for triclosan in the HS/LS states. The free-energy

224 barriers are high ( $>20 \mathrm{kcal} / \mathrm{mol})$, indicating that outer-sphere ET by P450 is unlikely for triclosan,

225 consistent with the much higher IPs of this phenolic substrate than the spin-averaged electron

226 affinities (EA) of only $2.9 \mathrm{eV}$ for Cpd I of P450. Although this study only focused on the outer-

227 sphere ET mechanism for triclosan, the results suggest that P450 is not able to catalyze 
228 efficiently the oxidative phenol coupling by HRP-like peroxidation, partly because the spin229 averaged EA of Cpd I of HRP $(6.0 \mathrm{eV})$ approaches the IPs of diverse phenolic substrates 230 (6.6-8.1 eV), including monophenols, bisphenols, polyphenols, alkylphenols and chlorophenols 231 (Table S20), and is thus much higher than EA of $2.9 \mathrm{eV}$ for Cpd I of P450.

\section{Inner-Sphere Oxidation Mechanism}

233 Free Energy Profiles for H-abstraction vs. O-addition. The free energy profiles for the

234 inner-sphere oxidation pathways of triclosan catalyzed by Cpd I of P450 are shown in Figure 1, 235 together with geometric details of the critical molecular species. The reactions start from reactant 236 complexes $\left({ }^{4,2} \mathrm{RC}_{\mathrm{H}}\right)$, in which the $\mathrm{H}$-atom of the phenolic group of triclosan interacts with the 237 iron-oxo moiety of Cpd I, existing in close-lying HS and LS spin states. ${ }^{4,2} \mathrm{RC}_{\mathrm{H}}$ can traverse $\mathrm{H}-$ 238 abstraction transition states ${ }^{4,2} \mathrm{TS}_{\mathrm{H}}$ (confirmed by almost linear $\mathrm{O} \cdot \bullet \cdot \mathrm{H} \bullet \bullet \mathrm{O}$ angles and high 239 imaginary frequencies), producing the intermediate complex ${ }^{4,2} \mathrm{IM}_{\mathrm{H}}$ with the iron-hydroxo 240 species (protonated Cpd II) and the phenoxy radical. And another pathway is O-addition onto the 241 aromatic ring of triclosan. We find the $\mathrm{H}$-abstraction pathway is the most favorable during inner242 sphere oxidation of triclosan and by $\mathrm{P} 450$, as reflected in reaction barriers for O-addition at all 243 unsubstituted aromatic carbons that are $21-27 \mathrm{kcal} / \mathrm{mol}$ higher than that for $\mathrm{H}$-abstraction. This is 244 in accordance with recent computational chemistry studies indicating that P450 GsfF performs 245 phenolic $\mathrm{O}-\mathrm{H}$ abstraction rather than $\mathrm{O}$-addition during catalyzed oxidation of griseophenone

246 B. ${ }^{74}$ In the oxidation of triclosan, the dispersion energies lower the H-abstraction barriers by 1.5 $247 \mathrm{kcal} / \mathrm{mol}$, in accord with previous findings. ${ }^{39,75}$

248 Compared to toluene, an archetypical substrate for understanding regioselectivity in P450 249 chemistry, according to our calculations, the O-H BDE of triclosan $(73.1 \mathrm{kcal} / \mathrm{mol})$ is distinctly 250 smaller than the $\mathrm{C}-\mathrm{H}$ BDE of toluene $(79.5 \mathrm{kcal} / \mathrm{mol})$, indicating that $\mathrm{H}$-abstraction is more likely 
251 to occur for triclosan than for toluene. And even toluene oxidation gives mostly benzyl alcohol 252 as $\mathrm{H}$-abstraction product beyond cresol as O-addition product of the phenyl group. ${ }^{76} \mathrm{We}$ further 253 computed the O-H BDEs for several other phenols such as monophenols, bisphenols, 254 polyphenols, alkylphenols and chlorophenols (Table S22). The O-H BDEs for these diverse 255 phenols are all within $68-74 \mathrm{kcal} / \mathrm{mol}$, distinctly smaller than the $\mathrm{C}-\mathrm{H}$ BDE of toluene, which 256 suggests that $\mathrm{P} 450$-catalyzed $\mathrm{H}$-abstraction is likely a common pathway during inner-sphere 257 oxidation of phenols.

\section{c.}

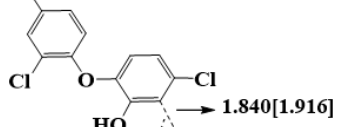

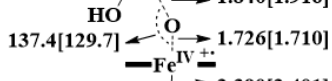
$\underset{\mathrm{SH}}{\stackrel{\mathrm{C}}{\longrightarrow} 2.390[2.401]}$ ${ }^{4} \mathrm{TS}_{\mathrm{O}_{0}}\left[{ }^{2} \mathrm{TS}_{\mathrm{O}_{0}}\right]$ $v_{\mathrm{im} .}=i 567.9 \mathrm{~cm}^{-1}\left[i 399.4 \mathrm{~cm}^{-1}\right]$

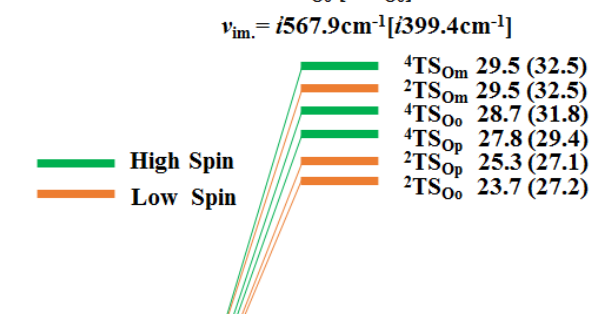
${ }^{4} \mathrm{RC}-0.2(-0.1)$

Cl

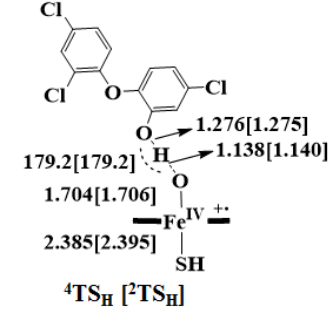

$v_{\mathrm{im} .}=i 1407.73 \mathrm{~cm}^{-1}\left[i 1421.98 \mathrm{~cm}^{-1}\right]$ ${ }^{2} \mathrm{IM}_{\mathrm{H}}$
$0.5(-0.9)$
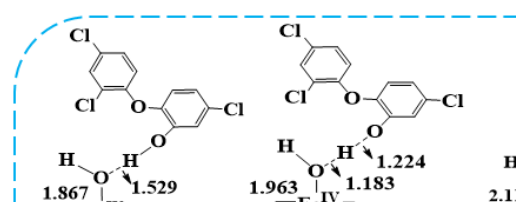

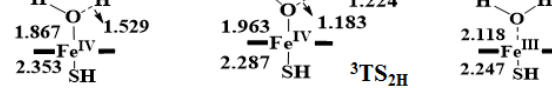

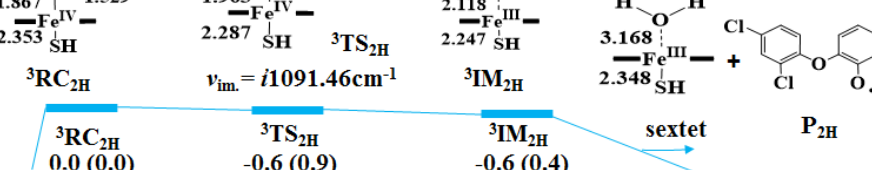
$\mathrm{H} \quad \mathbf{0 . 0}(0.0)$ $-\mathrm{Fe}^{\mathrm{IV}}-$ SH

$P_{2 \mathrm{H}}-12.7$ (-22.8) H

Cl
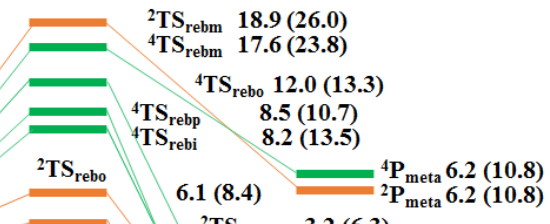

.1 (8.4) $\begin{array}{ll}{ }^{2} \mathrm{TS}_{\text {rebp }} & 3.2(6.3) \\ { }^{2} \mathrm{TS}_{\text {rebi }} & 1.2(8.4)\end{array}$
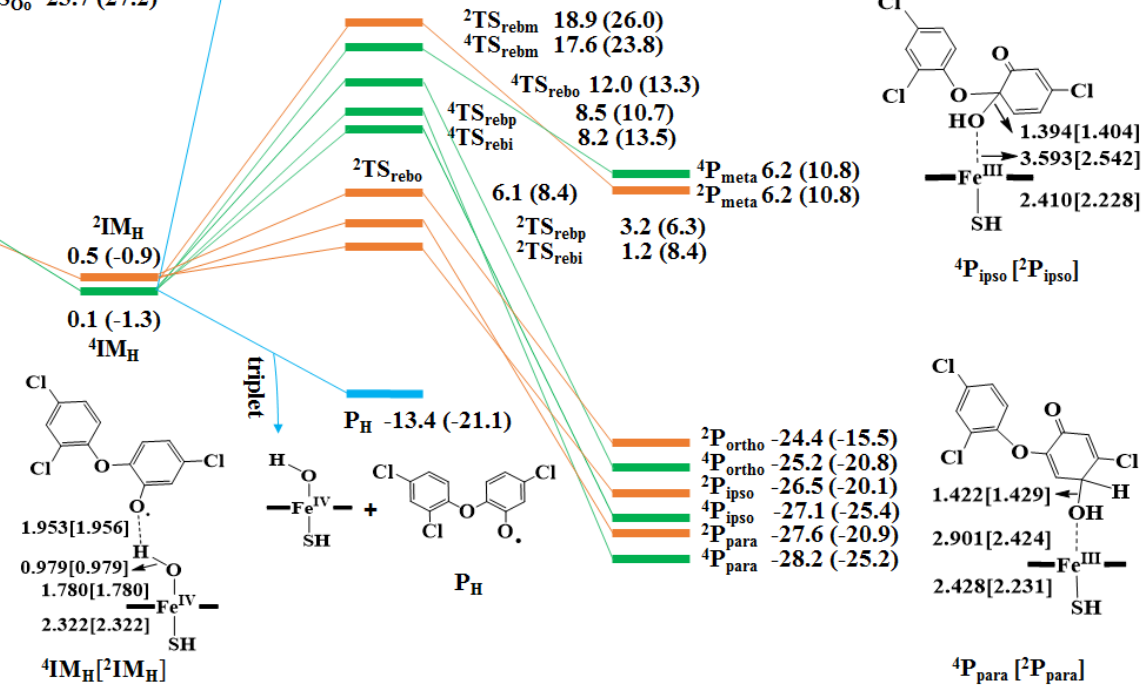
톻 $\frac{}{2} \sqrt{P_{\mathrm{H}}-13.4(-21.1)}$
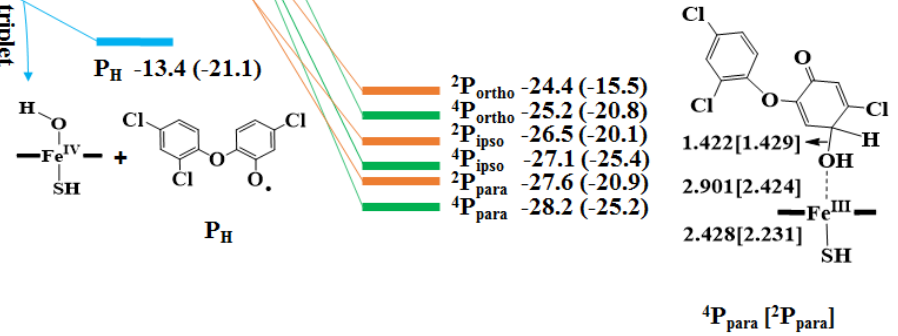

Figure 1. Free energy profiles for inner-sphere oxidation of triclosan by Cpd I of P450, along with the optimized geometries of the key reaction species in the HS and LS states. Free energies ( $\mathrm{kcal} / \mathrm{mol}$ ) are relative to the doublet reactant complex ${ }^{2} \mathrm{RC}$ including dispersion corrections (no parentheses) and without dispersion (in parentheses). Geometrical parameters (lengths in $\AA$ and angles in degrees) are shown as the HS [LS] state. For the transition states, the imaginary frequencies are shown. 
Two-State Reactivity Patterns in Hydroxylation. As shown in Figure 1, the intermediate

278

279

280

281

282

283

284

285

286

287

288

289

290

291

292

293

294

295

296

297

298

299

complex ${ }^{4,2} \mathrm{IM}_{\mathrm{H}}$ may lead to phenoxy radical rebound onto the hydroxo group of protonated Cpd II via its aromatic ring to yield the ortho-, meta-, para-, or ipso-addition quinol products in either spin state $\left({ }^{4,2} \mathrm{P}_{\text {ortho }},{ }^{4,2} \mathrm{P}_{\text {meta }},{ }^{4,2} \mathrm{P}_{\text {para }}\right.$ or $\left.{ }^{4,2} \mathrm{P}_{\text {ipso }}\right)$. The rebound reactions for the triclosan phenoxy radical at the ortho-, para- and ipso-carbon are highly exothermic, whereas the rebound reaction at the meta-carbon is highly endothermic. Considering the thermodynamically feasible rebound reactions, ${ }^{2} \mathrm{IM}_{\mathrm{H}}$ encounters minor barriers of $0.7 / 5.6 / 2.7 \mathrm{kcal} / \mathrm{mol}$ for the triclosan phenoxy radical rebound onto the ipso/ortho/para-carbon. In contrast, we find that the rebound barriers of ${ }^{4} \mathrm{IM}_{\mathrm{H}}$ onto corresponding aromatic carbons are typically $8-12 \mathrm{kcal} / \mathrm{mol}$ higher (or about 5-9 $\mathrm{kcal} / \mathrm{mol}$ higher than the barriers of the H-abstraction steps). Accordingly, formation of the quinol intermediates mostly occurs in the LS state, which can further evolve into the hydroxylated products. Note that without dispersion effects, the phenoxy radical rebound steps in both spin states are rate-determining, but the dispersion energies lower the rebound barriers by 1 $7 \mathrm{kcal} / \mathrm{mol}$, whereas the LS rebound barriers of the triclosan radical at ipso-carbon, used to be called "essentially barrierless". However, regardless of this important dispersion contribution, the mechanism involving LS rebound is consistently more favorable than the HS rebound.

In the LS state, the barrier for rebound of the triclosan phenoxy radical at the ipso-carbon is $2.0 \mathrm{kcal} / \mathrm{mol}$ lower than the corresponding reaction at the para-carbon. When comparing the respective rate-determining steps, $\mathrm{H}$-abstraction $(2.5 \mathrm{kcal} / \mathrm{mol})$ and radical rebound at the paracarbon $(3.2 \mathrm{kcal} / \mathrm{mol})$, considering a minor energy difference between ${ }^{2} \mathrm{P}_{\text {ipso }}$ and ${ }^{2} \mathrm{P}_{\text {para }}$, almost the same amount of quinols can be estimated. Accordingly, the most favorable quinol products formed in triclosan oxidation from both thermodynamical and kinetic considerations are expected to be ${ }^{2} \mathrm{P}_{\text {para }}$ and ${ }^{2} \mathrm{P}_{\text {ipso. }}{ }^{2} \mathrm{P}_{\text {para }}$ can further evolve into para-hydroxy-triclosan through 
300 tautomerization with an exothermic reaction free energy of $-22.8 \mathrm{kcal} / \mathrm{mol}$ (eq. 3 ), and ${ }^{2} \mathrm{P}_{\text {ipso }}$ can 301 lead to 2,4-dichlorophenol with 4-chloroquinone through H-transfer and ether bond breaking, 302 with an exothermic energy of $-11.5 \mathrm{kcal} / \mathrm{mol}$ (eq. 4). Human P450 are known to catalyze 303 hydroxylation of triclosan mainly at the para-position, with cleavage of the diphenyl ether bond 304 at the ipso-position giving rise to para-hydroxy-triclosan, 2,4-dichlorophenol and 4305 chlorocatechol, respectively. ${ }^{69}$ The exothermic free energies of our reaction profiles explain 306 these observations well.
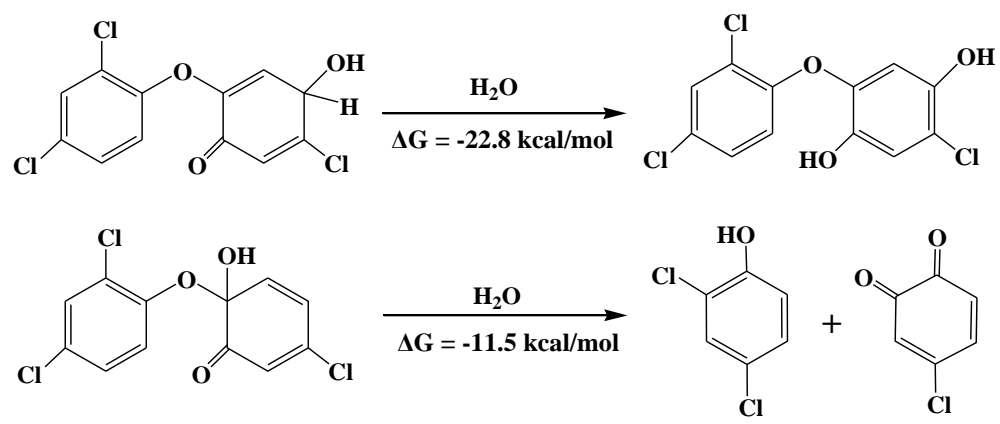

Secondary Phenolic H-Abstraction. Figure 1 also shows another pathway available to the

$309{ }^{4,2} \mathrm{IM}_{\mathrm{H}}$ intermediates, whose conversion into ferryl-hydroxo species and a free triclosan radical is 310 computed to be highly exothermic. Although their corresponding radical rebound reactions are 311 more exothermic, under kinetic control we predict that the dissociation for ${ }^{4} \mathrm{IM}_{\mathrm{H}}\left(\right.$ but not $\left.{ }^{2} \mathrm{IM}_{\mathrm{H}}\right)$ is 312 more favorable than radical rebound with higher barriers, and we expect the radical species in the 313 HS state can have large chance to detach. Note that the radical dissociation pathway has been 314 shown to be prominent along with $\mathrm{C}-\mathrm{H}$ hydroxylation by synthetic nonheme complexes (i.e. $315 \mathrm{Fe}^{\mathrm{IV}} \mathrm{O}, \mathrm{Mn}^{\mathrm{IV}} \mathrm{O}, \mathrm{Ru}^{\mathrm{IV}} \mathrm{O}$ et. al.), while subsequent theoretical work has shown the rebound barrier 316 is the key to determine the selectivity of radical rebound vs. radical dissociation. ${ }^{35}$ Similarly, the 317 triclosan phenoxy radical can leave the heme center unless other factors such as H-bonding 318 prevent dissociation. 
CYP158A1 and CYP158A2 have been shown to be able to catalyze the intermolecular

320

321

322

323

324

325

326

327

328

329

330

331

332

333

334

335

336

337

338

339

340

341 coupling of flaviolin in Streptomyces coelicolor A3(2), which are the only intermolecular coupling enzymes with known three-dimensional structures in the presence of two phenolic substrates in one pocket. ${ }^{77,78}$ Until now, no P450 isoforms has been reported to be responsible for phenol coupling of triclosan, we can make some hypothesis below. If the diradical coupling mechanism works, in case with enough space in the $\mathrm{P} 450$ protein pocket, the distal triclosan molecule may exchange with the proximal triclosan radical in the active site; Or in case that one P450 protein pocket is not enough to accommodate two molecules, the triclosan radical may leave the protein pocket and another triclosan molecule may enter into pocket near the heme center. In both situations, the formed reactant complexes $\left({ }^{3} \mathrm{RC}_{2 \mathrm{H}}\right)$, can then undergo $\mathrm{H}-$ abstraction from the phenolic group of triclosan by protonated Cpd II. As shown in the upright of Figure 1, this $\mathrm{H}$-abstraction from the phenolic group of triclosan by protonated Cpd II in the ground triplet state is essentially barrierless and is exothermic by $-12.7 \mathrm{kcal} / \mathrm{mol}$, with formation of the resting state of $\mathrm{P} 450$, and a triclosan phenoxy radical ready for radical collision.

Regioselectivity for Phenol Coupling. Considering the fate of phenoxy radicals involving radical addition or diradical coupling to yield the $\mathrm{C}-\mathrm{C} / \mathrm{C}-\mathrm{O}$ coupling products $(\mathrm{O}-\mathrm{O}$ coupling does not take place on account of the instability of the resultant peroxide), it is hard to obtain the structures of all coupling products in experiments due to their structural heterogeneities. However, the regioselectivity of phenol coupling is partially determined by the distribution of unpaired electron spin in the radicals, with a high electron spin density at a particular site indicating high reactivity. ${ }^{79}$ As shown in Figure 2, for non-substituted positions, O22 and C15 of the triclosan phenoxy radical are expected from this reasoning to be the two most reactive sites, as they have the largest spin densities. 


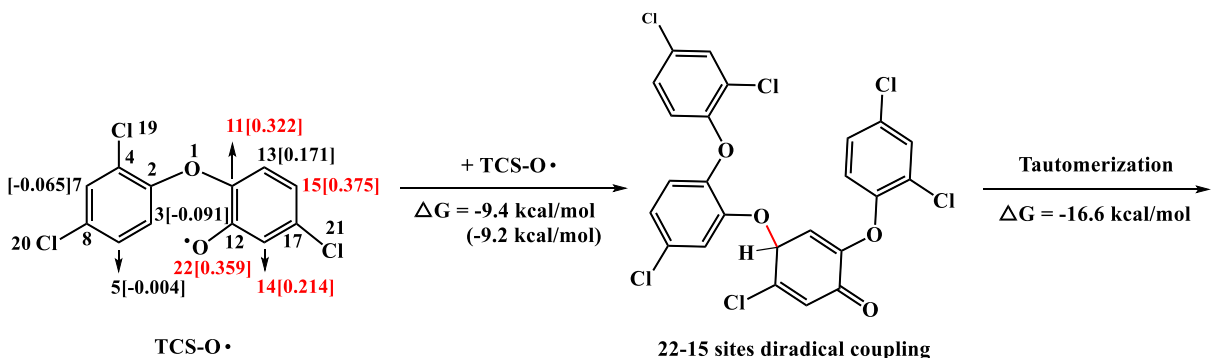

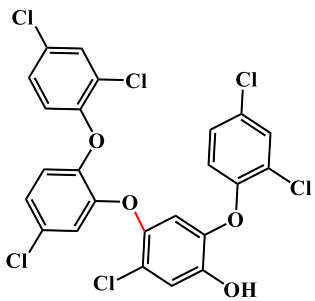

TCS-O-TCS

343 Figure 2. Spin densities for the triclosan phenoxy radical, and the most favorable diradical 344 coupling reactions and subsequent tautomerization reactions with computed reaction free 345 energies given (no parentheses: in polar environment; in parentheses: in non-polar environment).

346 We then speculate two possibilities, radical-addition or diradical coupling, for phenol 347 coupling, dependent on the environment based on no available protein structural concerning 348 phenol coupling of triclosan: 1) proximal triclosan radical addition to the distal neutral triclosan, 349 or diradical coupling, happen in one P450 protein pocket (non-polar environment); 2) the 350 phenoxy radical leaving the P450 pocket and reacting with another neutral phenol, or diradical 351 coupling, happen in solution outside of the P450 pocket (polar environment). Thus, to further 352 understand the linkage distributions during phenol coupling, a full study of the radical addition 353 and diradical couplings in both polar and non-polar solution was performed. As shown in Tables 354 S24-S25, all of the radical addition reactions are highly endothermic by $15-48 \mathrm{kcal} / \mathrm{mol}$ in polar 355 and $20-38 \mathrm{kcal} / \mathrm{mol}$ non-polar environments, probably due to the low radical nature of the 356 addition sites, and we thus focus on the diradical coupling reactions.

357 We studied the self-intermolecular coupling processes of triclosan phenoxy radical to form 358 the dimeric intermediates, during which a total of 14 coupling reactions shown in Tables 359 S26-S27 were considered to encompass different linkages and identify the most stable 360 stereoisomeric products. When analyzing these coupling reactions, C15-O22 (para C-O) 361 coupling as shown in Figure 2 emerges as the most likely coupling reaction with the most 362 exothermic energy of $-9.4 \mathrm{kcal} / \mathrm{mol}$ in the polar environment $(-9.2 \mathrm{kcal} / \mathrm{mol}$ in the non-polar 
363 environment), followed by $\mathrm{C} 11-\mathrm{O} 22, \mathrm{C} 14-\mathrm{O} 22, \mathrm{C} 14-\mathrm{C} 14, \mathrm{C} 15-\mathrm{C} 15$ and $\mathrm{C} 15-\mathrm{C} 14$ coupling 364 reactions with exothermic energies from -7.5 to $-2.9 \mathrm{kcal} / \mathrm{mol}$ in the polar environment $(-7.1$ to $3652.8 \mathrm{kcal} / \mathrm{mol}$ in the non-polar environment); all other coupling reactions involving the $\mathrm{C} 13$ site 366 are highly endothermic. These findings are very consistent with the spin density distributions on 367 the triclosan phenoxy radical $(\mathrm{C} 15 \approx \mathrm{O} 22>\mathrm{C} 14>>\mathrm{C} 13)$. Note just six triclosan-O-triclosan 368 metabolites were detected in mass spectra when triclosan was incubated with microsomes. ${ }^{10}$

369 Up to now, the favorable intermediates of radical coupling have been characterized. In most 370 cases where the ring has lost aromaticity, the intermediates may undergo tautomerization to 371 regain ring aromaticity in water solution. As shown in Figure 2, the energy of this 372 tautomerization reaction is $-16.6 \mathrm{kcal} / \mathrm{mol}$ for triclosan-O-triclosan formation in water solution.

373 The results indicate that the tautomerization step is thermodynamically favorable, since barriers 374 for hydrogen transfers through water bridging are small, and likely to yield the stable and fully 375 aromatic products. Note that the constitutive androstane receptor (CAR) activity of triclosan-O376 triclosan was reported to be about 7.2 times higher than that of triclosan. ${ }^{10}$

\section{Fundamental Characteristics of Phenoxy Radical Rebound}

378 Phenol Coupling vs. Phenol Hydroxylation. During P450-catalyzed alkane hydroxylation, 379 the HS state may produce a radical with a significant barrier for rebound, although still much 380 lower than that for the rate-determining H-abstraction step, whereas the LS state rebound is 381 essentially barrierless. ${ }^{31,33,34,36}$ Differently, oxidation of phenols such as triclosan, the real 382 rebound transition states may be both on the HS and LS surfaces. The phenoxy radical rebound 383 at some aromatic carbons in the LS state and at all aromatic carbons in the HS state are rate384 determining. With high rebound barriers for phenoxy radicals at the thermodynamically feasible 385 aromatic carbons, we propose a "two-state reactivity" as formulated in eq. 5 to eq. 7, which 
386 reflect different rebound conditions. 1) When the LS rebound barrier is lower at least at one 387 aromatic carbon and the HS rebound is higher than the H-abstraction barrier, most of the HS 388 intermediates can proceed via the coupling pathway, while the LS species can mostly proceed to 389 the hydroxylated products, giving the relative yield ratio [coupling]/[hydroxylation] of eq. 5 as 390 simply the relative barriers of the HS and LS H-abstraction processes, since $\mathrm{H}$-abstraction is the 391 rate-determining step for both pathways. 2) When the barrier for LS rebound at all aromatic 392 carbons is higher and the HS rebound barrier is distinctly higher than the H-abstraction barrier, 393 the LS species can be subject to both hydroxylation and coupling, whereas the HS species can 394 only proceed via coupling since the HS radical rebound is unfeasible; In this situation, as shown 395 in eq. 6, the ratio of yields [coupling]/[hydroxylation] is approximately given by the relative 396 barriers of the HS or LS H-abstraction (the lower one) and LS radical rebound steps, as these are 397 the favorable rate-determining steps for coupling and hydroxylation pathways, respectively. 3) 398 When both the LS and HS rebound steps have far higher barriers than the H-abstraction step, as 399 shown in eq. 7, the LS and HS species can only proceed via the coupling pathway.

$400 \quad$ When $\Delta \mathrm{G}_{\mathrm{LS} \text {-reb }}^{\ddagger}<\Delta \mathrm{G}_{\mathrm{LS} \text {-H }}^{\ddagger}$ and $\Delta \mathrm{G}_{\mathrm{HS} \text {-reb }}^{\ddagger}>\Delta \mathrm{G}_{\mathrm{HS}-\mathrm{H}}^{\ddagger}$ :

$401 \quad[$ Coupling $] /[$ Hydroxylation $] \approx \mathrm{k}_{\mathrm{HS}-\mathrm{H}} / \mathrm{k}_{\mathrm{LS}-\mathrm{H}}$

402 When $\Delta \mathrm{G}_{\mathrm{LS} \text {-reb }}^{\ddagger}>\Delta \mathrm{G}_{\mathrm{LS}-\mathrm{H}}^{\ddagger}$ and $\Delta \mathrm{G}_{\mathrm{HS} \text {-reb }}^{\ddagger}>\Delta \mathrm{G}_{\mathrm{HS}-\mathrm{H}}^{\ddagger}$ :

403 [Coupling] $]\left[\right.$ Hydroxylation] $\approx \mathrm{k}_{\mathrm{HS}-\mathrm{H}} / \mathrm{k}_{\mathrm{LS} \text {-reb }}$ if $\Delta \mathrm{G}_{\mathrm{HS}-\mathrm{H}}^{\ddagger}<\Delta \mathrm{G}_{\mathrm{LS}-\mathrm{H}}^{\ddagger}$

$404 \quad[$ Coupling] $] /[$ Hydroxylation $] \approx \mathrm{k}_{\mathrm{LS}-\mathrm{H}} / \mathrm{k}_{\mathrm{LS}-\text {-reb }}$ if $\Delta \mathrm{G}_{\mathrm{HS}-\mathrm{H}}^{\ddagger}>\Delta \mathrm{G}_{\mathrm{LS}-\mathrm{H}}^{\ddagger}$

405 When $\Delta \mathrm{G}_{\mathrm{LS} \text {-reb }}^{\ddagger}>\Delta \mathrm{G}_{\mathrm{LS}-\mathrm{H}}^{\ddagger}$ and $\Delta \mathrm{G}_{\mathrm{HS}-\text {-reb }}^{\ddagger}>\Delta \mathrm{G}_{\mathrm{HS}-\mathrm{H}}^{\ddagger}$ :

406 [Coupling $] /[$ Hydroxylation $] \approx \infty$ 
Based on the data provided in Figure 1, oxidation of triclosan by P450 fits well into the

408 situation of eq. 5. According to the model, we can estimate the ratio [coupling]/[hydroxylation]

409 using the Eyring equation (eq. 8) as roughly 1:4 for oxidation of triclosan $\left(\Delta \mathrm{G}_{\mathrm{HS}-\mathrm{H}}^{\ddagger}-\Delta \mathrm{G}_{\mathrm{LS}-\mathrm{H}}^{\ddagger}=\right.$

$410 \quad 0.8 \mathrm{kcal} / \mathrm{mol}$ ), which implies that the phenol hydroxylation is favorable for oxidation of triclosan.

$$
\mathrm{k}=\frac{\mathrm{k}_{\mathrm{B}} \mathrm{T}}{\mathrm{h}} \cdot \frac{1}{\mathrm{c}^{0}} \exp \left(-\frac{\Delta \mathrm{G}^{\ddagger}}{\mathrm{RT}}\right)
$$

412 k: reaction rate constant; $\mathrm{k}_{\mathrm{B}}$ : Boltzmann constant; h: Planck constant; R: gas constant; T: tempe-

413 rature in Kelvin; $\mathrm{c}^{0}$ : concentration defining the standard state (typically $1 \mathrm{~mol} / \mathrm{L}$ ).

414 This model largely explains the experimental ratios of the reaction rates of hydroxylation vs.

415 coupling in the range of (1.5-17):1 for triclosan incubated in human microsomes. ${ }^{10}$ In order to

416 further limit the effect of molecular specificity on phenol coupling mechanism obtained from

417 triclosan, we extended the study on the phenol coupling mechanism of 3-chloro-bisphenol A (3-

418 ClBPA), as the free energy profiles shown in Figure S5. It shows that 3-ClBPA resembles well

419 the phenol coupling mechanism of triclosan that a diradical pathway is successively facilitated

420 by Cpd I and protonated Cpd II of P450, thus we can estimate its ratio [coupling]/[hydroxylation]

421 as roughly 1:2 via eq. 5 and eq. 8. This result is in consistent with that 3-ClBPA-O-3-CIBPA is a

422 significant metabolite from 3-ClBPA incubated by P450 in experiment. ${ }^{10}$

423 Origin of the High Rebound Barrier for Phenoxy Radicals. As the spin densities show in

424 Table S3, the intermediate complexes $\left({ }^{4,2} \mathrm{IM}_{\mathrm{H}}\right)$ of the triclosan consist of an iron-hydroxo group

425 (PorFe $\left.{ }^{\mathrm{IV}} \mathrm{OH}\right)$ with a closed-shell porphyrin and a nearby phenoxy radical (electronic

426 configuration: $\delta \mathrm{x}^{2}-\mathrm{y}^{2} \pi_{\mathrm{xz}}^{*} \pi^{*}{ }_{\mathrm{yz}}^{1} \mathrm{a}_{2 \mathrm{u}}{ }^{2} \phi_{\mathrm{Rad}}{ }^{1}$ ). In the subsequent phenoxy radical rebound leading to the

427 iron-quinol species, the electron from the phenoxy radical shifts onto the low-lying orbitals $\left(\pi^{*}{ }_{x z}\right)$

428 in the LS state, while the HS process involves the electron shifting onto the high-lying $\sigma^{*} z^{2}$ 
429 orbital to conserve the HS state, with elongation of the $\mathrm{Fe}-\mathrm{O}$ and $\mathrm{Fe}-\mathrm{S}$ bond lengths in the quinol

430 products (Figure 1). Previous studies on alkane hydroxylation mechanisms catalyzed by P450

431 have indicated that the HS rebound barriers for the alkyl radicals are $1-5 \mathrm{kcal} / \mathrm{mol}$, owing to the 432 excitation energy to the $\sigma^{*} \mathrm{z}^{2}$ orbital. ${ }^{31,32,34,40,41}$ This electron excitation partly contributes to the 433 high HS rebound barrier of the phenoxy radical, but is not enough to cause the HS rebound 434 barrier more than $8 \mathrm{kcal} / \mathrm{mol}$ and even a significant rebound barriers in the LS state.

435 Table 2. The calculated spin delocalization ratios, SOMOs and IPs for diverse phenoxy and 436 alkylbenzene radicals

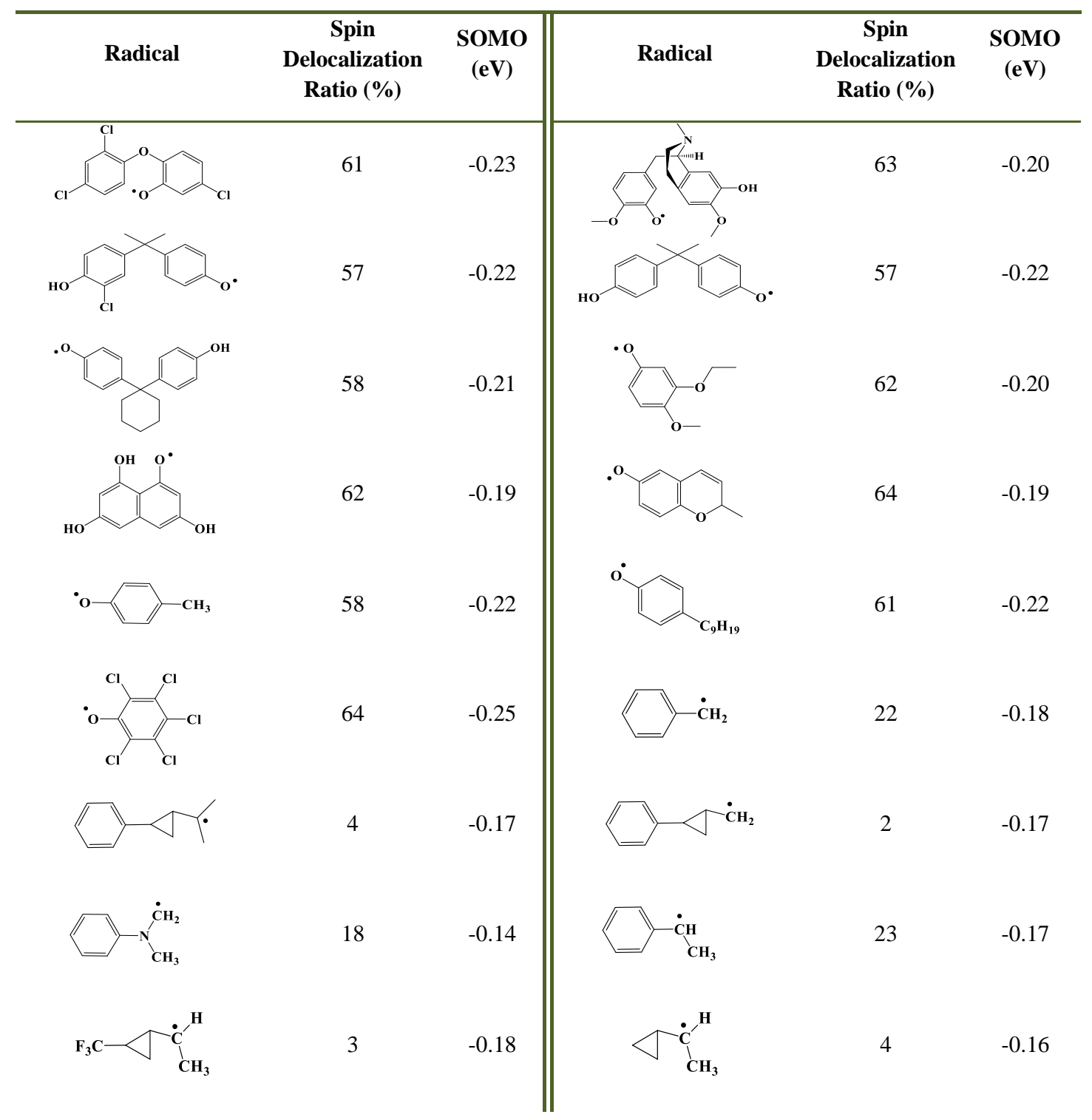




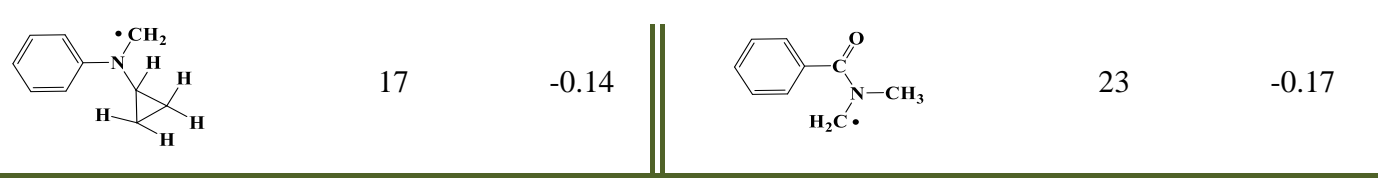

As shown in Table 2, the radical spin formed initially on the hydroxyl oxygen can readily

439 delocalize into the aromatic ring $(58 \%-64 \%)$ in monophenols, bisphenols, polyphenols,

440 alkylphenols and chlorophenols, while little spin delocalization occurs for several common

441 alkylbenzene radicals (2\%-23\%). Spin delocalization may result in lower electron donor ability

442 of the phenoxy radicals, as reflected in Table 2 by the significantly lower energies of the singly

443 occupied molecular orbitals (SOMOs) of phenoxy radicals in the range from -0.25 to $-0.19 \mathrm{eV}$,

444 compared to alkylbenzene radicals (between -0.18 and $-0.14 \mathrm{eV}$ ). Thus, another factor leading to

445 the high rebound barriers in phenol coupling by P450 could be the low electron donor ability of

446 the phenoxy radicals. In order to further understand this, we compared the computed HS rebound

447 barrier heights (B3LYP/BSI level with free energy correction, Table S32) with the phenolic

448 radical IPs (Table $\mathbf{S 3 3}$ as shown in Figure 3. The trend demonstrates an increase of rebound

449 barrier heights with increasing phenolic radical IPs, which strongly suggests that when the

450 phenoxy radical center becomes a weaker electron donor (higher IP), the rebound barrier

451 increases. Considering the very strong correlation, we conclude that the electron donor ability of

452 the phenoxy radicals is the main factor determining the barrier height of rebound, and this

453 physical model for P450 rebound reactivity may be of substantial use in many other contexts of 454 P450 chemistry. 


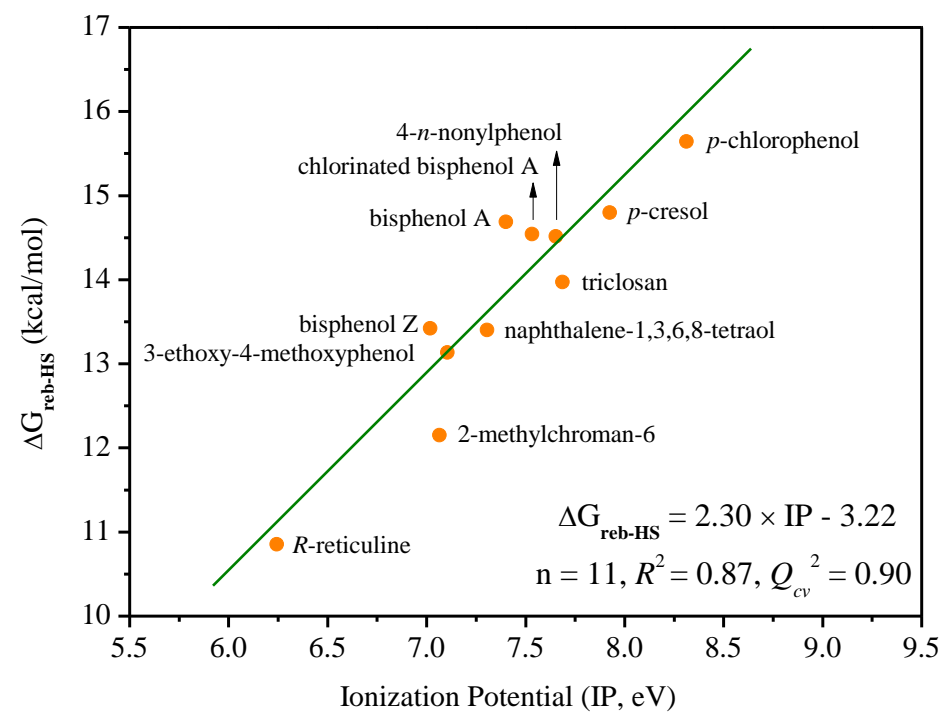

456 Figure 3. Correlation of rebound barrier heights in the HS state with the IPs of diverse phenolic 457 radicals

\section{Environmental Implications}

Most emerging pollutants proceed through the biotransformation processes, especially by P450 enzymes, which may produce metabolites with altering environmental behavior and toxicological profile. Especially, it has been found that as the number of aromatic rings increase,

462 there is a concomitant increase in lipophilicity of the compounds, ${ }^{80}$ resulting in potentially higher 463 toxicity, and thus the biotransformation involving coupling reactions of emerging phenolic 464 pollutants has important environmental significance. Understanding the biotransformation 465 mechanisms of emerging pollutants such as phenol coupling to develop mechanism-based 466 methods for screening of metabolites will undoubtedly improve the efficiency of metabolites467 oriented analysis in environmental risk assessment. As the mechanism revealed in this work, 468 aromatic delocalization is arguably the decisive factor that lowers the electron donor ability of 469 triclosan phenoxy radical and enables radical dissociation and self-coupling reaction catalyzed 470 by P450 enzymes. Furthermore, aromatic delocalization as an intrinsic nature for most phenolic 
471 pollutants (Table 2), which can endow the phenoxy radical sufficient lifetime during P450-

472 mediated reactions, thus the phenol coupling reactions have great chance to happen between

473 different phenolic pollutants when they co-exposure to the biotransformation system. As more

474 attention has been paid in the joint metabolic effect of multiple environmental chemicals

475 recently, ${ }^{81}$ our proposed phenol coupling mechanism can be helpful to screen the possible cross-

476 coupling metabolites between different phenolic pollutants, as a leading step of experiments.

477 Aromatic delocalization is a common feature also of other radicals of aromatic pollutants,

478 i.e. benzenamino radicals, thiophenoxy radicals, and phenylphosphine radicals (for example, the

479 spin delocalization ratio is $55 \%$ for $2,6-\left(\mathrm{CH}_{3}\right)_{2} \mathrm{C}_{6} \mathrm{H}_{3} \mathrm{NH} \bullet$, $70 \%$ for $\mathrm{C}_{6} \mathrm{H}_{5} \mathrm{~S} \bullet$, and $87 \%$ for

$480 \mathrm{C}_{6} \mathrm{H}_{5} \mathrm{PH} \bullet$ ), and thus we predict that they may undergo coupling reactions as well. P450-catalyzed

481 coupling of norharman and aniline has been reported, and this coupling product can be further

482 oxidized into a mutagenic hydroxylamine. ${ }^{82}$ However, it is difficult to propose a reaction product

483 of either norharman or aniline that is stable enough to migrate from the P450 and reactive

484 enough to couple with aniline, or vice versa. The phenol coupling mechanism proposed in this

485 work provides a simple rationale for this disputed coupling mechanism. The free energy profile

486 for the reaction of norharman catalyzed by Cpd I of P450 is displayed in Figure S6, specially

487 showing much higher rebound barriers for the norharman amino radical than for H-abstraction in

488 the HS state to lead to aromatic hydroxylation and the N-hydroxylation products. In contrast, the

489 rebound barriers for the norharman amino radical at the aromatic ring in the LS state are slightly

490 lower than for H-abstraction; this situation is importantly covered by our model's first scenario,

491 eq. 5, where the HS H-abstraction (leading to coupling) is more favorable than the LS

492 counterpart (leading to hydroxylation), and the model can thus explain the observation of

493 coupling products upon oxidation of norharman. In both norharman and aniline amino radicals, 
494 about $50 \%$ and $40 \%$ radical spin delocalizes into the aromatic rings from the amino nitrogen. 495 Aromatic delocalization in amino radicals may produce large radical rebound barriers, further 496 facilitating radical dissociation and coupling reaction. We hope that the fundamental mechanism

497 described in this work will aid the high-throughput screening of putative metabolites of aromatic 498 pollutants in toxicological assays, in particular considering the probable overlooked importance 499 of many of these metabolites.

\section{ASSOCIATED CONTENT}

501 Supporting Information. Optimized structures of the molecular species involved in P450502 catalyzed triclosan pathway optimized at the B3LYP/BSII level; Evaluation of the solvation 503 effect in P450-catalyzed triclosan pathway with SMD solvation model; Details for quantum 504 chemical cluster calculations; Estimation of activation barriers for electron transfer processes by 505 Marcus theory; Potential energy profiles for P450-catalyzed 3-chloro-bisphenol A pathway; 506 Potential energy profiles for P450-catalyzed norharman pathway; Mulliken spin densities and 507 charges; Energies for all molecular species; Cartesian coordinates of all structures. This material 508 is available free of charge via the Internet at http://pubs.acs.org.

\section{AUTHOR INFORMATION}

\section{Corresponding Author}

$511 * *($ L.J.) E-mail: jilienv@zju.edu.cn

\section{Author Contributions}

$513 \quad$ F. G. and L. C. contribute equally to this work. 


\section{Notes}

516 The authors declare no competing financial interest.

518 ACKNOWLEDGMENT

519 This work was supported by the National Natural Science Foundation of China (No. 21677125)

520 and Japan Society for the Promotion of Science (No. 19524). The China National 521 Supercomputing Center in Shenzhen is acknowledged for providing the computing resources.

\section{REFERENCES}

523 (1) Tang, M. C.; Zou, Y.; Watanabe, K.; Walsh, C. T.; Tang, Y. Oxidative cyclization in 524 natural product biosynthesis. Chem. Rev. 2017, $117(8), 5226-5333$.

525 (2) Mizutani, M.; Sato, F. Unusual p450 reactions in plant secondary metabolism. Arch. 526 Biochem. Biophys. 2011, 507 (1), 194-203.

527 (3) Woithe, K.; Geib, N.; Zerbe, K.; Li, D. B.; Heck, M.; Fournier-Rousset, S.; Meyer, O.; 528 Vitali, F.; Matoba, N.; Abou-Hadeed, K.; Robinson, J. A. Oxidative phenol coupling reactions 529 catalyzed by oxyb: A cytochrome p450 from the vancomycin producing organism. Implications 530 for vancomycin biosynthesis. J. Am. Chem. Soc. 2007, 129 (21), 6887-6895.

531 (4) Guengerich, F. P. Common and uncommon cytochrome p450 reactions related to 532 metabolism and chemical toxicity. Chem. Res. Toxicol. 2001, 14 (6), 611-650.

533 (5) Liu, R. Z.; Song, S. J.; Lin, Y. F.; Ruan, T.; Jiang, G. B. Occurrence of synthetic phenolic 534 antioxidants and major metabolites in municipal sewage sludge in china. Environ. Sci. Technol. 535 2015, $49(4), 2073-2080$. 
(6) Wang, W.; Asimakopoulos, A. G.; Abualnaja, K. O.; Covaci, A.; Gevao, B.; Johnson537 Restrepo, B.; Kumosani, T. A.; Malarvannan, G.; Minh, T. B.; Moon, H. B.; Nakata, H.; Sinha, 538 R. K.; Kannan, K. Synthetic phenolic antioxidants and their metabolites in indoor dust from 539 homes and microenvironments. Environ. Sci. Technol. 2016, 50 (1), 428-434.

(7) Mizukawa, H.; Nomiyama, K.; Nakatsu, S.; Yamamoto, M.; Ishizuka, M.; Ikenaka, Y.;

541 Nakayama, S. M. M.; Tanabe, S. Anthropogenic and naturally produced brominated phenols in 542 pet blood and pet food in japan. Environ. Sci. Technol. 2017, 51 (19), 11354-11362.

543 (8) Wang, X. Y.; Hou, X. W.; Zhou, Q. F.; Liao, C. Y.; Jiang, G. B. Synthetic phenolic 544 antioxidants and their metabolites in sediments from the coastal area of northern china: Spatial 545 and vertical distributions. Environ. Sci. Technol. 2018, 52 (23), 13690-13697.

546 (9) Wang, X. Y.; Hou, X. W.; Hu, Y.; Zhou, Q. F.; Liao, C. Y.; Jiang, G. B. Synthetic 547 phenolic antioxidants and their metabolites in mollusks from the chinese bohai sea: Occurrence, 548 temporal trend, and human exposure. Environ. Sci. Technol. 2018, 52 (17), 10124-10133.

549 (10) Ashrap, P.; Zheng, G. M.; Wan, Y.; Li, T.; Hu, W. X.; Li, W. J.; Zhang, H.; Zhang, Z. B.; $550 \mathrm{Hu}, \mathrm{J}$. Y. Discovery of a widespread metabolic pathway within and among phenolic xenobiotics. 551 Proc. Natl. Acad. Sci. U. S. A. 2017, 114 (23), 6062-6067.

552 (11) Barton, D. H. R.; Cohen, T., Some biogenetic aspects of phenol oxidation. In Festschrift 553 prof. Dr. Arthur stoll, Birkhauser Verlag: Basel, 1957; p 117-144.

554 (12) Rittle, J.; Green, M. T. Cytochrome p450 compound i: Capture, characterization, and c-h 555 bond activation kinetics. Science 2010, 330 (6006), 933-937. 
(13) Mittra, K.; Green, M. T. Reduction potentials of p450 compounds i and ii: Insight into the thermodynamics of c-h bond activation. J. Am. Chem. Soc. 2019, 141 (13), 5504-5510.

(14) Grobe, N.; Zhang, B.; Fisinger, U.; Kutchan, T. M.; Zenk, M. H.; Guengerich, F. P.

559 Mammalian cytochrome p450 enzymes catalyze the phenol-coupling step in endogenous 560 morphine biosynthesis. J. Biol. Chem. 2009, 284 (36), 24425-24431.

(15) Belin, P.; Le Du, M. H.; Fielding, A.; Lequin, O.; Jacquet, M.; Charbonnier, J.-B.; Lecoq,

562 A.; Thai, R.; Courcon, M.; Masson, C.; Dugave, C.; Genet, R.; Pernodet, J.-L.; Gondry, M.

563 Identification and structural basis of the reaction catalyzed by cyp121, an essential cytochrome 564 p450 in mycobacterium tuberculosis. Proc. Natl. Acad. Sci. U. S. A. 2009, 106 (18), 7426-7431.

(16) Ohe, T.; Mashino, T.; Hirobe, M. Substituent elimination from $p$-substituted phenols by 566 cytochrome p450. Ipso-substitution by the oxygen atom of the active species. Drug Metab. 567 Dispos. 1997, $25(1), 116-122$.

568 (17) Sarabia, S. F.; Zhu, B. T.; Kurosawa, T.; Tohma, M.; Liehr, J. G. Mechanism of 569 cytochrome p450-catalyzed aromatic hydroxylation of estrogens. Chem. Res. Toxicol. 1997, 10 $570 \quad(7), 767-771$.

571 (18) Stresser, D. M.; Kupfer, D. Catalytic characteristics of cyp3a4: Requirement for a 572 phenolic function in ortho hydroxylation of estradiol and mono-o-demethylated methoxychlor. 573 Biochemistry 1997, $36(8), 2203-2210$.

574 (19) Ehlting, J.; Hamberger, B.; Million-Rousseau, R.; Werck-Reichhart, D. Cytochromes 575 p450 in phenolic metabolism. Phytochem. Rev. 2006, 5 (2-3), 239-270. 
576 (20) Sono, M.; Roach, M. P.; Coulter, E. D.; Dawson, J. H. Heme-containing oxygenases. 577 Chem. Rev. 1996, 96 (7), 2841-2887.

578 (21) Poulos, T. L., In The porphyrin handbook, 2000; Vol. 4, pp 189-218.

579 (22) Dawson, J. H. Probing structure-function relations in heme-containing oxygenases and 580 peroxidases. Science 1988, 240 (4851), 433-439.

(23) Berglund, G. I.; Carlsson, G. H.; Smith, A. T.; Szoke, H.; Henriksen, A.; Hajdu, J. The 582 catalytic pathway of horseradish peroxidase at high resolution. Nature 2002, 417 (6887), 463583468.

584 (24) de Visser, S. P.; Shaik, S.; Sharma, P. K.; Kumar, D.; Thiel, W. Active species of 585 horseradish peroxidase (hrp) and cytochrome p450: Two electronic chameleons. J. Am. Chem. 586 Soc. 2003, $125(51), 15779-15788$.

587 (25) Meyer, A. H.; Dybala-Defratyka, A.; Alaimo, P. J.; Geronimo, I.; Sanchez, A. D.; Cramer, 588 C. J.; Elsner, M. Cytochrome p450-catalyzed dealkylation of atrazine by rhodococcus sp. Strain 589 ni86/21 involves hydrogen atom transfer rather than single electron transfer. Dalton Trans 2014, $59043(32), 12175-12186$.

(26) Li, Y.; Shi, X.; Zhang, Q.; Hu, J.; Chen, J.; Wang, W. Computational evidence for the 592 detoxifying mechanism of epsilon class glutathione transferase toward the insecticide ddt. 593 Environ. Sci. Technol. 2014, 48 (9), 5008-5016.

594 (27) Sadowsky, D.; McNeill, K.; Cramer, C. J. Dehalogenation of aromatics by nucleophilic 595 aromatic substitution. Environ. Sci. Technol. 2014, 48 (18), 10904-10911. 
(28) Krzeminska, A.; Paneth, P. Dft studies of sn2 dechlorination of polychlorinated biphenyls.

597 Environ. Sci. Technol. 2016, 50 (12), 6293-6298.

(29) Pati, S. G.; Kohler, H. P.; Pabis, A.; Paneth, P.; Parales, R. E.; Hofstetter, T. B. Substrate

599 and enzyme specificity of the kinetic isotope effects associated with the dioxygenation of 600 nitroaromatic contaminants. Environ. Sci. Technol. 2016, 50 (13), 6708-6716.

601 (30) Fu, Z. Q.; Wang, Y.; Chen, J. W.; Wang, Z. Y.; Wang, X. B. How pbdes are transformed 602 into dihydroxylated and dioxin metabolites catalyzed by the active center of cytochrome p450s: 603 A dft study. Environ. Sci. Technol. 2016, 50 (15), 8155-8163.

604 (31) Ogliaro, F.; Harris, N.; Cohen, S.; Filatov, M.; de Visser, S. P.; Shaik, S. A model 605 "rebound" mechanism of hydroxylation by cytochrome p450: Stepwise and effectively concerted 606 pathways, and their reactivity patterns. J. Am. Chem. Soc. 2000, 122 (37), 8977-8989.

607 (32) Yoshizawa, K.; Kamachi, T.; Shiota, Y. A theoretical study of the dynamic behavior of 608 alkane hydroxylation by a compound i model of cytochrome p450. J. Am. Chem. Soc. 2001, 123 609 (40), 9806-9816.

610 (33) Shaik, S.; Cohen, S.; Wang, Y.; Chen, H.; Kumar, D.; Thiel, W. P450 enzymes: Their 611 structure, reactivity, and selectivity-modeled by qm/mm calculations. Chem. Rev. 2010, 110 (2), $612949-1017$.

613 (34) Shaik, S.; Kumar, D.; de Visser, S. P. Valence bond modeling of trends in hydrogen 614 abstraction barriers and transition states of hydroxylation reactions catalyzed by cytochrome 615 p450 enzymes. J. Am. Chem. Soc. 2008, 130 (31), 10128-10140. 
616 (35) Cho, K. B.; Hirao, H.; Shaik, S.; Nam, W. To rebound or dissociate? This is the

617 mechanistic question in c-h hydroxylation by heme and nonheme metal-oxo complexes. Chem.

618 Soc. Rev. 2016, 45 (5), 1197-1210.

619 (36) Shaik, S.; Kumar, D.; de Visser, S. P.; Altun, A.; Thiel, W. Theoretical perspective on the 620 structure and mechanism of cytochrome p450 enzymes. Chem. Rev. 2005, 105 (6), 2279-2328.

621 (37) de Visser, S. P.; Ogliaro, F.; Shaik, S. How does ethene inactivate cytochrome p450 en 622 route to its epoxidation? A density functional study. Angewandte Chemie-International Edition $6232001,40(15), 2871-2874$.

624 (38) Ji, L.; Schuurmann, G. Computational evidence for alpha-nitrosamino radical as initial 625 metabolite for both the $\mathrm{p} 450$ dealkylation and denitrosation of carcinogenic nitrosamines. J. Phys. 626 Chem. B 2012, $116(2), 903-912$.

627 (39) Ji, L.; Faponle, A. S.; Quesne, M. G.; Sainna, M. A.; Zhang, J.; Franke, A.; Kumar, D.; 628 van Eldik, R.; Liu, W. P.; de Visser, S. P. Drug metabolism by cytochrome p450 enzymes: What 629 distinguishes the pathways leading to substrate hydroxylation over desaturation? Chem. Eur. J. $630 \quad \mathbf{2 0 1 5}, 21(25), 9083-9092$.

631 (40) de Visser, S. P.; Ogliaro, F.; Sharma, P. K.; Shaik, S. What factors affect the 632 regioselectivity of oxidation by cytochrome p450? A dft study of allylic hydroxylation and 633 double bond epoxidation in a model reaction. J. Am. Chem. Soc. 2002, 124 (39), 11809-11826.

634 (41) Shaik, S.; Cohen, S.; de Visser, S. P.; Sharma, P. K.; Kumar, D.; Kozuch, S.; Ogliaro, F.; 635 Danovich, D. The "rebound controversy": An overview and theoretical modeling of the rebound 636 step in c-h hydroxylation by cytochrome p450. Eur. J. Inorg. Chem. 2004, (2), 207-226. 
(42) Company, A.; Prat, I.; Frisch, J. R.; Mas-Balleste, R.; Gueell, M.; Juhasz, G.; Ribas, X.;

638 Muenck, E.; Luis, J. M.; Que, L., Jr.; Costas, M. Modeling the cis-oxo-labile binding site motif

639 of non-heme iron oxygenases: Water exchange and oxidation reactivity of a non-heme iron(iv)-

640 oxo compound bearing a tripodal tetradentate ligand. Chem. Eur. J. 2011, 17 (5), 1622-1634.

641 (43) Janardanan, D.; Usharani, D.; Chen, H.; Shaik, S. Modeling c-h abstraction reactivity of 642 nonheme fe(iv)o oxidants with alkanes: What role do counter ions play? J. Phys. Chem. Lett. 643 2011, $2(20), 2610-2617$.

644 (44) Cho, K.-B.; Shaik, S.; Nam, W. Theoretical investigations into c-h bond activation 645 reaction by nonheme mn(iv)o complexes: Multistate reactivity with no oxygen rebound. J. Phys. 646 Chem. Lett. 2012, 3 (19), 2851-2856.

647 (45) Cho, K. B.; Wu, X.; Lee, Y. M.; Kwon, Y. H.; Shaik, S.; Nam, W. Evidence for an 648 alternative to the oxygen rebound mechanism in c-h bond activation by non-heme fe(iv)o 649 complexes. J. Am. Chem. Soc. 2012, 134 (50), 20222-20225.

650 (46) Ji, L.; Ji, S.; Wang, C.; Kepp, K. P. Molecular mechanism of alternative p450-catalyzed 651 metabolism of environmental phenolic endocrine-disrupting chemicals. Environ. Sci. Technol. 652 2018, $52(7), 4422-4431$.

653 (47) Schyman, P.; Lai, W.; Chen, H.; Wang, Y.; Shaik, S. The directive of the protein: How 654 does cytochrome p450 select the mechanism of dopamine formation? J. Am. Chem. Soc. 2011, $655133(20), 7977-7984$.

656 (48) Ji, L.; Schuurmann, G. Model and mechanism: N-hydroxylation of primary aromatic 657 amines by cytochrome p450. Angew. Chem. Int. Ed. 2013, 52 (2), 744-748. 
(49) Zhang, Q.; Ji, S.; Chai, L.; Yang, F.; Zhao, M.; Liu, W.; Schueuermann, G.; Ji, L. 659 Metabolic mechanism of aryl phosphorus flame retardants by cytochromes $\mathrm{p} 450$ : A combined 660 experimental and computational study on triphenyl phosphate. Environ. Sci. Technol. 2018, 52 $661 \quad(24), 14411-14421$. 663 formula into a functional of the electron-density. Phys. Rev. B: Condens. Matter Mater. Phys. 664 1988, $37(2), 785-789$.

(51) Becke, A. D. Density-functional thermochemistry. Iii. The role of exact exchange. $J$. Chem. Phys. 1993, 98 (7), 5648-5652.

(52) Hay, P. J.; Wadt, W. R. Abinitio effective core potentials for molecular calculations potentials for the transition-metal atoms sc to hg. J. Chem. Phys. 1985, 82 (1), 270-283.

(53) Kumar, D.; de Visser, S. P.; Shaik, S. How does product isotope effect prove the operation of a two-state "rebound" mechanism in c-h hydroxylation by cytochrome p450? J. Am. Chem. Soc. 2003, 125 (43), 13024-13025.

672 (54) Porro, C. S.; Kumar, D.; de Visser, S. P. Electronic properties of pentacoordinated heme 673 complexes in cytochrome p450 enzymes: Search for an fe(i) oxidation state. Phys. Chem. Chem. 674 Phys. 2009, 11 (43), 10219-10226.

675 (55) Strickland, N.; Harvey, J. N. Spin-forbidden ligand binding to the ferrous-heme group: 676 Ab initio and dft studies. J. Phys. Chem. B 2007, 111 (4), 841-852.

677 (56) Altun, A.; Breidung, J.; Neese, F.; Thiel, W. Correlated ab initio and density functional 678 studies on h2 activation by feo ${ }^{+} . J$. Chem. Theory Comput. 2014, 10 (9), 3807-3820. 
679 (57) Tao, J.; Perdew, J. P.; Staroverov, V. N.; Scuseria, G. E. Climbing the density functional 680 ladder: Nonempirical meta-generalized gradient approximation designed for molecules and 681 solids. Phys. Rev. Lett. 2003, 91 (14), 146401.

682 (58) Staroverov, V. N.; Scuseria, G. E.; Tao, J. M.; Perdew, J. P. Comparative assessment of a 683 new nonempirical density functional: Molecules and hydrogen-bonded complexes. J. Chem. 684 Phys. 2003, $119(23), 12129-12137$.

685 (59) Perdew, J. P.; Wang, Y. Accurate and simple analytic representation of the electron-gas 686 correlation energy. Phys. Rev. B: Condens. Matter Mater. Phys. 1992, 45 (23), 13244-13249.

687 (60) Becke, A. D. Density-functional exchange-energy approximation with correct 688 asymptotic-behavior. Phys. Rev. A: At., Mol., Opt. Phys. 1988, 38 (6), 3098-3100.

689 (61) Adamo, C.; Barone, V. Exchange functionals with improved long-range behavior and 690 adiabatic connection methods without adjustable parameters: The mpw and mpw1pw models. $J$. 691 Chem. Phys. 1998, $108(2), 664-675$.

692 (62) Zhao, Y.; Truhlar, D. G. A new local density functional for main-group thermochemistry, 693 transition metal bonding, thermochemical kinetics, and noncovalent interactions. J. Chem. Phys. 694 2006, $125(19), 194101$.

695 (63) Miertus, S.; Scrocco, E.; Tomasi, J. Electrostatic interaction of a solute with a continuum 696 - a direct utilization of abinitio molecular potentials for the prevision of solvent effects. Chem. 697 Phys. 1981, 55 (1), 117-129. 
(64) Ogliaro, F.; de Visser, S. P.; Cohen, S.; Kaneti, J.; Shaik, S. The experimentally elusive oxidant of cytochrome p450: A theoretical "trapping" defining more closely the "real" species. ChemBioChem 2001, 2 (11), 848-851.

(65) Marenich, A. V.; Cramer, C. J.; Truhlar, D. G. Universal solvation model based on solute electron density and on a continuum model of the solvent defined by the bulk dielectric constant and atomic surface tensions. J. Phys. Chem. B 2009, 113 (18), 6378-6396.

(66) Grimme, S. Semiempirical gga-type density functional constructed with a long-range dispersion correction. J. Comput. Chem. 2006, 27 (15), 1787-1799.

(67) Himo, F. Recent trends in quantum chemical modeling of enzymatic reactions. J. Am. Chem. Soc. 2017, 139 (20), 6780-6786.

(68) Senn, H. M.; Thiel, W. Qm/mm methods for biomolecular systems. Angew. Chem. Int. Ed. Engl. 2009, 48 (7), 1198-1229.

(69) Wu, Y. F.; Chitranshi, P.; Loukotkova, L.; da Costa, G. G.; Beland, F. A.; Zhang, J.;

711 Fang, J. L. Cytochrome p450-mediated metabolism of triclosan attenuates its cytotoxicity in 712 hepatic cells. Arch. Toxicol. 2017, 91 (6), 2405-2423.

713 (70) Frisch, M. J.; Trucks, G. W.; Schlegel, H. B.; Scuseria, G. E.; Robb, M. A.; Cheeseman, J. 714 R.; Scalmani, G.; Barone, V.; Mennucci, B.; Petersson, G. A.; Nakatsuji, H.; Caricato, M.; Li, X.; 715 Hratchian, H. P.; Izmaylov, A. F.; Bloino, J.; Zheng, G.; Sonnenberg, J. L.; Hada, M.; Ehara, M.; 716 Toyota, K.; Fukuda, R.; Hasegawa, J.; Ishida, M.; Nakajima, T.; Honda, Y.; Kitao, O.; Nakai, H.; 717 Vreven, T.; Montgomery, J. A.; Jr.; Peralta, J. E.; Ogliaro, F.; Bearpark, M.; Heyd, J. J.; Brothers, 718 E.; Kudin, K. N.; Staroverov, V. N.; Kobayashi, R.; Normand, J.; Raghavachari, K.; Rendell, A.; 
719 Burant, J. C.; Iyengar, S. S.; Tomasi, J.; Cossi, M.; Rega, N.; Millam, N. J.; Klene, M.; Knox, J. 720 E.; Cross, J. B.; Bakken, V.; Adamo, C.; Jaramillo, J.; Gomperts, R.; Stratmann, R. E.; Yazyev, 721 O.; Austin, A. J.; Cammi, R.; Pomelli, C.; Ochterski, J. W.; Martin, R. L.; Morokuma, K.; 722 Zakrzewski, V. G.; Voth, G. A.; Salvador, P.; Dannenberg, J. J.; Dapprich, S.; Daniels, A. D.; 723 Farkas, Ö.; Foresman, J. B.; Ortiz, J. V.; Cioslowski, J.; Fox, D. J. Gaussian, Inc.: Wallingford 724 CT, 2013. Gaussian 09, Revision D.01.

725 (71) Marcus, R. A. Electron-transfer reactions in chemistry - theory and experiment (nobel 726 lecture). Angew. Chem. Int. Ed. 1993, 32 (8), 1111-1121.

727 (72) Jones, G. O.; Liu, P.; Houk, K. N.; Buchwald, S. L. Computational explorations of 728 mechanisms and ligand-directed selectivities of copper-catalyzed ullmann-type reactions. J. Am. 729 Chem. Soc. 2010, 132 (17), 6205-6213.

730 (73) Lin, C. Y.; Coote, M. L.; Gennaro, A.; Matyjaszewski, K. Ab initio evaluation of the 731 thermodynamic and electrochemical properties of alkyl halides and radicals and their 732 mechanistic implications for atom transfer radical polymerization. J. Am. Chem. Soc. 2008, 130 733 (38), 12762-12774.

734 (74) Grandner, J. M.; Cacho, R. A.; Tang, Y.; Houk, K. N. Mechanism of the p450-catalyzed 735 oxidative cyclization in the biosynthesis of griseofulvin. ACS Catal. 2016, 6 (7), 4506-4511.

736 (75) Lonsdale, R.; Harvey, J. N.; Mulholland, A. J. Inclusion of dispersion effects 737 significantly improves accuracy of calculated reaction barriers for cytochrome p450 catalyzed 738 reactions. J. Phys. Chem. Lett. 2010, 1 (21), 3232-3237. 
739 (76) Tassaneeyakul, W.; Birkett, D. J.; Edwards, J. W.; Veronese, M. E.; Tassaneeyakul, W.;

740 Tukey, R. H.; Miners, J. O. Human cytochrome p450 isoform specificity in the regioselective 741 metabolism of toluene and o-, m- and p-xylene. J. Pharmacol. Exp. Ther. 1996, 276 (1), 101-108.

742 (77) Zhao, B.; Guengerich, F. P.; Bellamine, A.; Lamb, D. C.; Izumikawa, M.; Lei, L.; Podust, 743 L. M.; Sundaramoorthy, M.; Kalaitzis, J. A.; Reddy, L. M.; Kelly, S. L.; Moore, B. S.; Stec, D.; 744 Voehler, M.; Falck, J. R.; Shimada, T.; Waterman, M. R. Binding of two flaviolin substrate 745 molecules, oxidative coupling, and crystal structure of streptomyces coelicolor a3(2) cytochrome 746 p450 158a2. J. Biol. Chem. 2005, 280 (12), 11599-11607.

747 (78) Zhao, B.; Lamb, D. C.; Lei, L.; Kelly, S. L.; Yuan, H.; Hachey, D. L.; Waterman, M. R. 748 Different binding modes of two flaviolin substrate molecules in cytochrome p450 158a1 749 (cyp158a1) compared to cyp158a2. Biochemistry 2007, 46 (30), 8725-8733.

750 (79) Sangha, A. K.; Parks, J. M.; Standaert, R. F.; Ziebell, A.; Davis, M.; Smith, J. C. Radical 751 coupling reactions in lignin synthesis: A density functional theory study. J. Phys. Chem. B 2012, $752116(16), 4760-4768$.

753 (80) Ritchie, T. J.; Macdonald, S. J. The impact of aromatic ring count on compound 754 developability--are too many aromatic rings a liability in drug design? Drug Discov. Today 2009, $755 \quad 14(21-22), 1011-1020$.

756 (81) Peng, B.; Liu, M.; Han, Y.; Wanjaya, E. R.; Fang, M. L. Competitive biotransformation 757 among phenolic xenobiotic mixtures: Underestimated risks for toxicity assessment. Environ. Sci. 758 Technol. 2019, 53 (20), 12081-12090. 
759 (82) Totsuka, Y.; Hada, N.; Matsumoto, K.; Kawahara, N.; Murakami, Y.; Yokoyama, Y.;

760 Sugimura, T.; Wakabayashi, K. Structural determination of a mutagenic aminophenylnorharman

761 produced by the co-mutagen norharman with aniline. Carcinogenesis 1998, 19 (11), 1995-2000.

762

763

764

765

766

767

768

769

770

771

772

773

774

775 


\section{SYNOPSIS GRAPHICS}

777

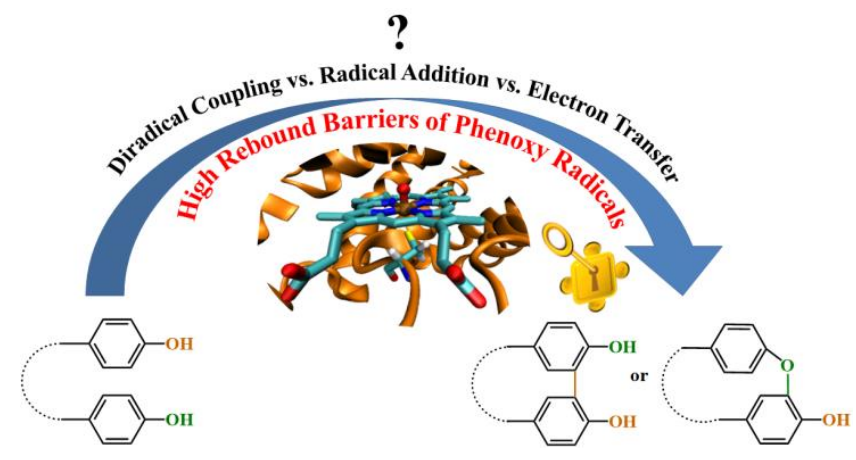

778 
Cl Énvironmental Science \& Technology

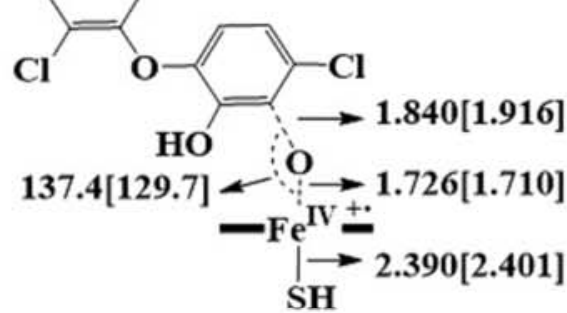

${ }^{4} \mathrm{TS}_{\mathrm{O}_{0}}\left[{ }^{2} \mathrm{TS}_{\mathrm{O}_{0}}\right]$ $v_{\text {im. }}=i 567.9 \mathrm{~cm}^{-1}\left[i 399.4 \mathrm{~cm}^{-1}\right]$

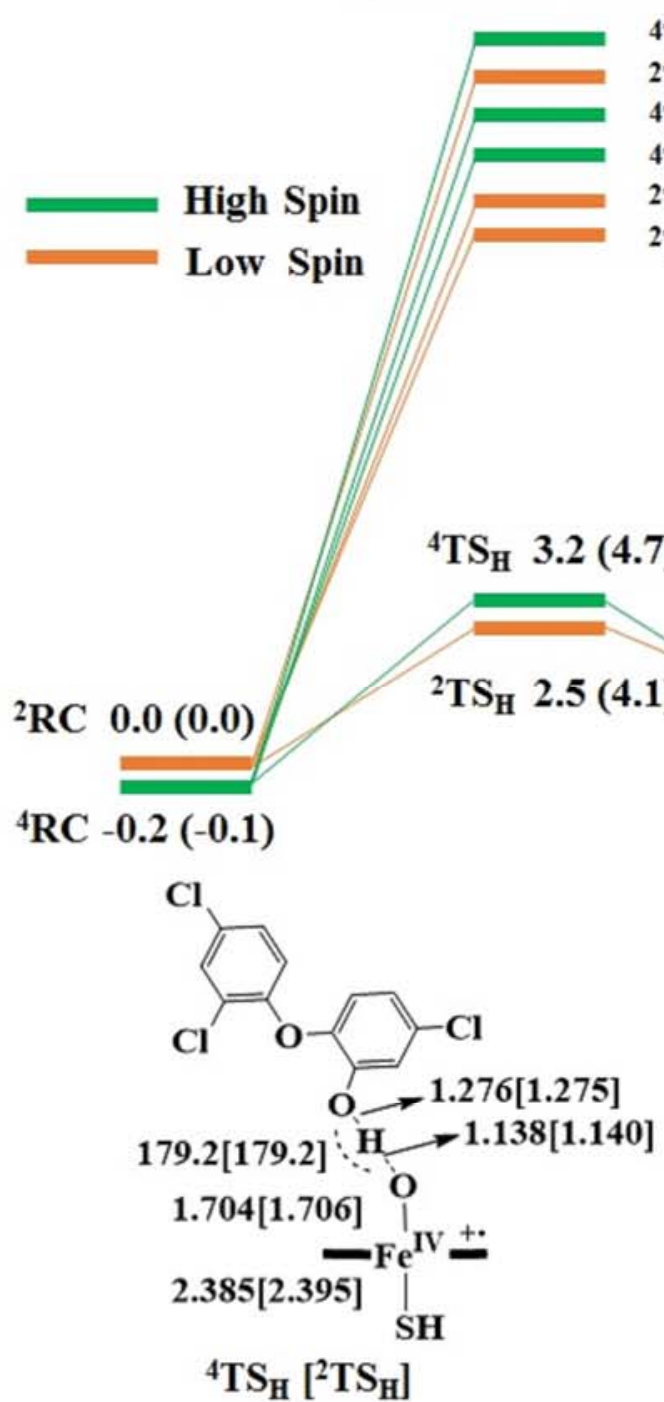

$v_{\text {im. }}=i 1407.73 \mathrm{~cm}^{-1}\left[i 1421.98 \mathrm{~cm}^{-1}\right]$

${ }^{4} \mathrm{TS}_{\mathrm{Om}} 29.5$ (32.5)

${ }^{2} \mathrm{TS}_{\mathrm{Om}} 29.5$ (32.5)

${ }^{4} \mathrm{TS}_{\mathrm{O}_{0}} 28.7(31.8)$

${ }^{4} \mathrm{TS}_{\mathrm{Op}} 27.8(29.4)$

${ }^{2} \mathrm{TS}_{\mathrm{Op}} 25.3(27.1)$

${ }^{2} \mathrm{TS}_{\mathrm{O}} 23.7(27.2)$<smiles>Oc1cc(Cl)ccc1Oc1ccccc1Cl</smiles>

1.867 ( 1.529

$2.353 \mathrm{Fe}_{\mathrm{SH}}^{\mathrm{IV}}-\quad 2.287{ }_{\mathrm{SH}}^{-\mathrm{Fe}^{\mathrm{N}}-}{ }^{3} \mathrm{TS}_{2 \mathrm{H}}$

${ }^{3} \mathrm{RC}_{2 \mathrm{H}}$

$0.0(0.0) \quad-0.6(0.9)$

$-\mathrm{Fe}^{\mathrm{IV}}-$

SH

${ }^{2} \mathrm{TS}_{\text {rebo }}$

${ }^{2} \mathrm{IM}_{\mathrm{H}}$

$0.5(-0.9)$

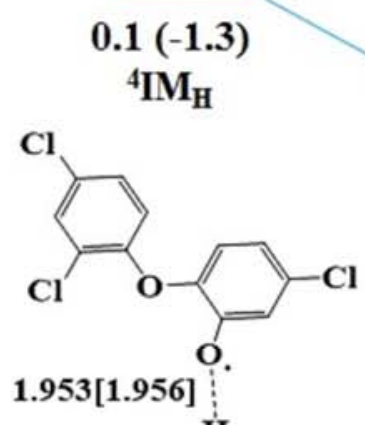

$0.979[0.979] \stackrel{\mathrm{H}}{\sim} \mathrm{O}$

른 $\quad \frac{P_{H}-13.4(-21.1)}{\Xi}$

$\mathrm{Cl}$

Page 40 of 40

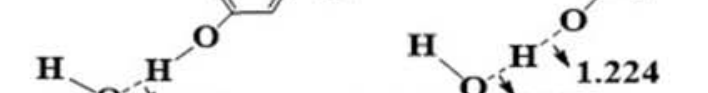

1.963 O 1.183

$v_{\text {im. }}=i 1091.46 \mathrm{~cm}^{-1}$

$\mathrm{H}_{\mathrm{O}^{\prime}} \mathrm{H}^{\prime}$ i.68s

2.118 (1II- 1.688

$\frac{118}{2.247} \mathrm{Fe}$

${ }^{3} \mathrm{IM}_{2 \mathrm{H}}$
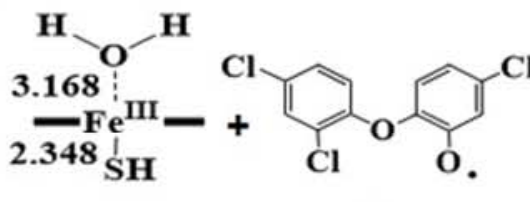

${ }^{3} \mathrm{RC}_{2 \mathrm{H}} \quad{ }^{3} \mathrm{TS}_{2 \mathrm{H}} \quad{ }^{3} \mathrm{IM}_{2 \mathrm{H}} \quad$ sextet $\quad P_{2 \mathrm{H}}$

$-0.6(0.4)$

$\mathrm{P}_{2 \mathrm{H}}-12.7$ (-22.8)

Cl

${ }^{2} \mathrm{TS}_{\text {rebm }} 18.9(26.0)$

${ }^{4} \mathrm{TS}_{\text {rebm }} 17.6(23.8)$

${ }^{4} \mathrm{TS}_{\text {rebo }} 12.0(13.3)$
${ }^{4} \mathrm{TS}_{\text {rebp }} \quad 8.5(10.7)$

${ }^{4} \mathrm{TS}_{\text {rebi }} \quad 8.2(13.5)$
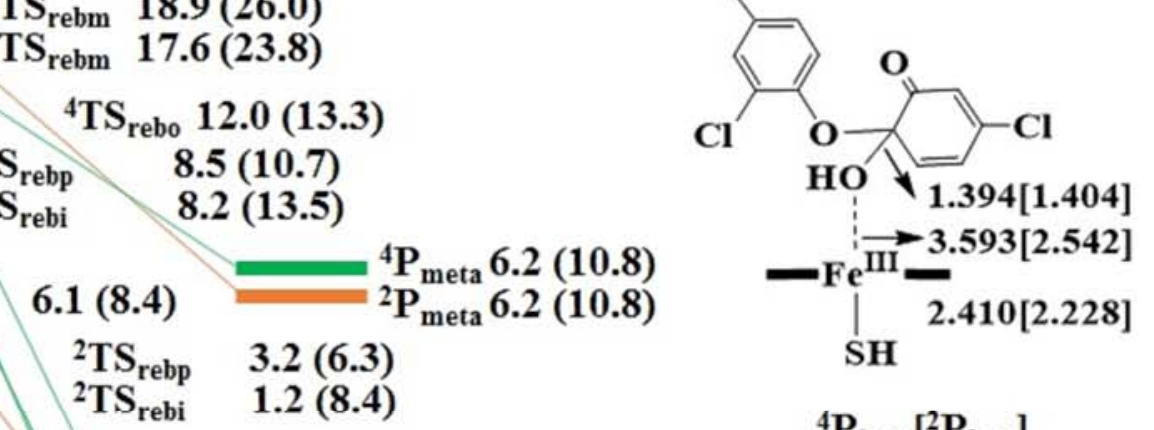

${ }^{2} \mathrm{TS}_{\text {rebi }} 1.2(8.4)$

${ }^{4} \mathbf{P}_{\text {ipso }}\left[{ }^{2} \mathbf{P}_{\text {ipso }}\right]$

$2.322[2.322]$

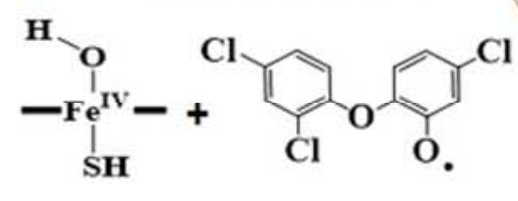

${ }^{2} P_{\text {ortho }}-24.4$ (-15.5)

${ }^{2} \mathbf{P}_{\text {ortho }} \mathbf{P}_{\text {ortho }}-25.2(-20.8)$
${ }^{2} \mathbf{P}_{\text {ipso }}-26.5(-20.1)$

${ }^{4} \mathrm{P}_{\mathrm{ipso}}-27.1(-25.4)$

${ }^{2} \mathrm{P}_{\mathrm{P}}-27.6(-20.9)$

${ }^{4} \mathbf{P}_{\text {para }}-28.2(-25.2)$

$\mathbf{P}_{\mathbf{H}}$

Cl

${ }^{4} I_{M_{H}}\left[{ }^{2} \mathbf{I M}_{H}\right]$

ACS Paragon Plus Environment

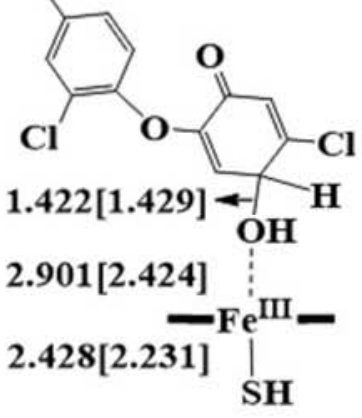

${ }^{4} \mathbf{P}_{\text {para }}\left[{ }^{2} \mathbf{P}_{\text {para }}\right]$ 